Pre-publication copy.

Published in: The Journal of Experimental Psychology: Animal Learning \& Cognition, 45, 2019.

(CAmerican Psychological Association, 2019. This paper is not the copy of record and may not exactly replicate the authoritative document published in the APA journal. Please do not copy or cite without author's permission. The final article is available, upon publication.

\title{
The Partial-Reinforcement Extinction Effect Does Not Result from Reduced Sensitivity to Non-Reinforcement
}

\author{
Justin A. Harris, Manuel S. Seet, \& Dorothy W. S. Kwok \\ School of Psychology, University of Sydney
}

Address correspondence to:

Justin Harris

School of Psychology

The University of Sydney,

Sydney 2006

Australia

Running head: The PREE and sensitivity to non-reinforcement

Acknowledgements. This research was supported by funding from the Australian Research Council, grant DP 150101274. 


\begin{abstract}
Five experiments used a magazine approach paradigm with rats to investigate whether learning about non-reinforcement is impaired in the presence of a conditioned stimulus (CS) that had been partially reinforced (PRf). Experiment 1 trained rats with a PRf CS and a continuously reinforced (CRf) CS, then extinguished responding to both CSs presented together as a compound. Probe trials of each CS presented alone revealed that extinction was slower for the PRf CS than the CRf CS, despite being extinguished in compound. In Experiment 2, a CRf light was extinguished in compound with either a CRf CS or a PRf CS that had been matched for overall reinforcement rate. Responding to the light extinguished at the same rate regardless of the reinforcement schedule of the other CS. Experiment 3 replicated this result with a PRf light. Thus, we found no evidence that a PRf CS impairs extinction of another CS presented at the same time. Experiments 4 and 5 extended this approach to study the acquisition of conditioned inhibition by training an inhibitor in compound with either a PRf or CRf excitatory CS. The reinforcement schedule of the excitatory CS had no effect on the acquisition of inhibition. In sum, conditioning with a PRf schedule slows subsequent extinction of that CS but does not affect learning about the non-reinforcement of other stimuli presented at the same time. We conclude that the Partial Reinforcement Extinction Effect is not due to a decrease in sensitivity to non-reinforcement following presentation of a PRf CS.
\end{abstract} Key words: Partial Reinforcement, Extinction, Conditioned Inhibition, Reinforcement Rate, Compound. 
The Partial-Reinforcement Extinction Effect (PREE) is one of the best-known phenomena in associative learning, having been extensively studied in both instrumental and Pavlovian conditioning preparations for over 50 years (Fitzgerald, 1963; Fitzgerald, Vardaris, \& Teyler, 1966; Humphrey, 1939, 1940; Jenkins, 1950; Wagner, Siegel, Thomas, \& Ellison, 1964; Weinstock, 1954). It refers to the fact that a response conditioned using a "partial" (i.e., inconsistent) reinforcement schedule is more resistant to subsequent extinction than the same response conditioned using a "continuous" (consistent) reinforcement schedule. The two leading accounts of the PREE explain it in terms of differences in the generalisation of responding from conditioning to extinction. According to Amsel's Frustration Theory (Amsel, $1958,1962)$, once an animal learns that an instrumental response or a Pavlovian conditioned stimulus (CS) is followed by a reward or unconditioned stimulus (US), subsequent nonreinforced trials (in which the response or CS occurs without the reward or US) evoke a reaction of frustration. If the animal is trained with consistent reinforcement, it only experiences frustration, as a reaction to non-reinforcement, during the subsequent extinction phase, and therefore this state helps to reduce generalisation of responding from conditioning to extinction and so promotes response loss. If the animal is trained on a partial reinforcement schedule, in which non-reinforced trials were intermixed among reinforced ones, it regularly experiences frustration during conditioning and, therefore, the animal acquires conditioned responding in the presence of that state. As a result, its frustration as a reaction to non-reinforcement during extinction helps to maintain responding in the animal. A similar, though more nuanced, account of the PREE was described in Capaldi's Sequential Theory (Capaldi, 1966, 1994). In this account, animals do not simply learn about CS-US (or response-reward) associations as simple dyads, but they learn about sequences of CS-US or response-reward pairings. Thus, during consistent reinforcement, the animal not only learns 
that the CS is followed by the US, or the response is followed by the reward, but they also learn that each reinforced trial is followed by another reinforced trial. The unexpected occurrence of non-reinforcement during subsequent extinction breaks this pattern, resulting in a generalisation decrement. By contrast, during partial reinforcement, the animal learns that non-reinforced trials are part of a sequence that leads up to reinforcement, which ensures that the animal persists in responding in the face of non-reinforcement during extinction.

According to the theories described above, the PREE can be understood, at least in part, as a performance effect. That is, the resistance to extinction after partial reinforcement can be attributed to superior generalisation of responding from conditioning to extinction, without any consideration of differences in what animals might learn from each nonreinforced trial during extinction (Mackintosh, 1974). However, it is also possible that the persistence of responding during extinction after partial reinforcement reflects differences in sensitivity to, and learning about, non-reinforcement. For example, the frequent experience of non-reinforcement during a partial reinforcement schedule might promote habituation of the frustration reaction (Weinstock, 1954), and so reduce the impact of non-reinforcement as an outcome that drives new learning during extinction. Alternatively, if animals trained with a partial reinforcement schedule expect reinforcement only after a sequence of nonreinforced trials (Capaldi, 1994), this could slow learning during extinction by changing the significance of many instances of non-reinforcement. This process is made explicit in some information-based theories of learning that argue that responding extinguishes once the animal detects that it has missed a critical number of USs, and that conditioning with partial reinforcement slows extinction because it reduces the frequency with which the US is expected and thus missed (Gallistel, 2012; Gallistel \& Gibbon, 2000). By each account, the 
effective salience of non-reinforcement is reduced, impairing what animals learn during extinction about the outcome of non-reinforcement.

Rescorla (1999a) conducted a series of experiments to test the idea that training on a partial reinforcement schedule impairs subsequent learning about non-reinforcement. He trained pigeons in an autoshaped key pecking procedure with one keylight, that was reinforced on $100 \%$ of trials, and a second keylight reinforced on $25 \%$ of trials. The next phase included trials in which each keylight was presented in compound with a diffuse stimulus and these trials were not reinforced, thereby establishing the diffuse stimuli as conditioned inhibitors. Across a series of experiments, Rescorla found evidence that the diffuse stimulus paired with the $100 \%$ keylight acquired stronger inhibition than the diffuse stimulus paired with the $25 \%$ keylight. This result is consistent with the suggestion that partial reinforcement reduced the pigeons' sensitivity to non-reinforcement because this would predict weaker or slower inhibitory conditioning to the diffuse stimulus that was paired with the $25 \%$ keylight.

Two of Rescorla's (1999a) experiments were designed to rule out a simpler alternative explanation - that the net excitatory strength of the $25 \%$ keylight was weaker than that of the $100 \%$ keylight and thus less able to impart inhibitory strength on its partnered diffuse stimulus. In one experiment, the $25 \%$ keylight was put on a $100 \%$ reinforcement schedule just prior to the inhibitory conditioning phase with the diffuse stimuli to equate responding (and presumed excitatory strength) between the two keylights. In the other experiment, the $100 \%$ keylight was conditioned using a 10-s trace interval (filled with another stimulus) to reduce responding to (and presumed excitatory strength of) that CS to a level below that of the $25 \%$ keylight. In both experiments, Rescorla still found weaker inhibitory strength conditioned to the diffuse stimulus paired with the $25 \%$ keylight, even though that keylight evokes as much 
or even more responding than the $100 \%$ keylight. Rescorla concluded that the history of partial reinforcement of the $25 \%$ keylight reduced the pigeons' sensitivity to nonreinforcement of that CS and, as a result, reduced learning when that CS was not reinforced. This same decrease in sensitivity to non-reinforcement could contribute to resistance to extinction after partial reinforcement.

It is worth noting that all of Rescorla's (1999a) experiments used within-subjects designs. Therefore, the effect of the partial reinforcement training could not be due to a general change in sensitivity to non-reinforcement, such as simple habituation of the frustration response, since this would impact on learning about non-reinforcement for both diffuse stimuli equally. This adds to other evidence that the PREE itself can be obtained in within-subjects designs (Chan \& Harris, 2017, 2019; Crawford, Steirn, \& Pavlik, 1985; Harris \& Kwok, 2018; Harris, Kwok, \& Gottlieb, submitted; Rescorla, 1999b). Therefore, whatever mechanism is responsible for these effects must involve changes that are stimulus-specific, rather than a generalised effect on learning or performance.

Rescorla's (1999a) aim was to test the idea that the PREE is due to a loss in sensitivity to non-reinforcement. However, because his experiments examined the acquisition of conditioned inhibition rather than extinction, his results only provide indirect evidence concerning the mechanisms of the PREE. The current series of experiments were devised to address this gap. The first three experiments used an approach similar to that adopted by Rescorla (1999a) to examine whether partial reinforcement affects subsequent learning about non-reinforcement during extinction. We trained rats in a magazine approach paradigm with CSs that were paired with food on either a 33\% partial reinforcement (PRf) schedule or a consistent reinforcement (CRf) schedule. Next, we extinguished responding to 
the CSs in compound, while using single-stimulus probe trials to assess the progress of extinction of each individual CS. Experiment 1 confirmed the presence of a PREE even when the PRf CS and CRf CS were extinguished as a compound. Experiment 2 tested whether extinction of a CRf target CS differs depending on whether it is extinguished in compound with a PRf CS or a CRf CS. Experiment 3 replicated Experiment 2 except that the target CS had itself been conditioned with a PRf schedule prior to extinction in compound. Neither of these experiments provided any evidence that extinction of the target CS was affected by the reinforcement schedule of the CS with which it was extinguished. In other words, it appeared that partial reinforcement did not affect learning about non-reinforcement reflected in the extinction of a neutral CS. In light of this, Experiment 4 and 5 sought to replicate Rescorla's (1999a) evidence for a difference in acquisition of conditioned inhibition as a function of the reinforcement schedule of the excitatory CS.

In the five experiments presented here, the timing of the food US relative to onset of the CS (the CS-US interval) varied randomly from trial to trial, and the average duration of this interval was three times longer for the CRf CS than the PRf CS (30 s versus 10 s). The difference in length matches the two CSs for the total rate of reinforcement per unit time (one US for every $30 \mathrm{~s}$ of CS presentation). The random variation in CS-US interval prevents the rats from learning to estimate when the US occurs and, as a result, the response rates to the CSs are constant across the length of each trial rather than being timed to the CS-US interval (Harris, 2015; Harris, Gharaei, \& Pincham, 2011). The combination of these methods ensures that the acquisition of responding to the CRf and PRf CSs is well matched (Harris, Patterson, \& Gharaei, 2015), which solves the problem faced by Rescorla (1999a) when comparing the acquisition of conditioned inhibition using a CRf CS and a PRf CS that differed in how much responding they elicited. 


\section{Experiment 1}

We have recently confirmed two earlier demonstrations (Crawford et al., 1985; Rescorla, 1999b) of a PREE using a within-subjects design. In our experiments, rats were concurrently trained with a partially reinforced CS (PRf) and a consistently reinforced CS (CRf), before responding to both CSs was extinguished. Across 7 different experiments, we have observed that responding to the PRf CS took longer to extinguish than to the CRf CS (Chan \& Harris, 2017, 2019; Harris \& Kwok, 2018; Harris et al., submitted). These within-subjects demonstrations of the PREE are important because they show that whatever process is responsible for the difference in rate of extinction, that process must involve learning that is specific to the partially reinforced CS. In addition, the within-subjects design provides an opportunity to examine extinction of responding to a partially and a consistently reinforced CS when the two CSs are presented together in compound. This is useful because it provides a test of the hypothesis that the PREE is a learning effect (a reduction in learning about nonreinforcement) rather than a performance effect. If extinction of a PRf CS is slower than extinction of a CRf CS because the animal is less sensitive to learning about non-reinforcement when it follows presentations of the PRf CS, then the difference in extinction would be eliminated when the two CSs are presented simultaneously because any difference in sensitivity to non-reinforcement would affect learning about both CSs equally. Therefore, Experiment 1 tested this prediction by training rats with a PRf CS and a CRf CS, before repeatedly presenting the two CSs together in compound under extinction (without reinforcement). To assess how responding extinguished to each of the CSs individually, each extinction session with the compound CS included one probe trial in which the PRf CS was presented on its own, and one probe trial in which the CRf CS was presented on its own. The design is summarised in Table 1. If, during the probe trials, responding to the PRf CS declines 
at the same rate as responding to the CRf CS, this would support the idea that the PREE, which is observed when the CSs are extinguished separately, is due to a difference in learning about the outcome of non-reinforcement on trials with the PRf CS.

Table 1 about here

\section{Methods}

\section{Subjects}

Sixteen experimentally-naive female albino Sprague Dawley rats ( 8 to 10 weeks of age) were obtained from Animal Resources Centre, Perth, Western Australia. They were housed in groups of 4 in split-level ventilated plastic tubs (Techniplast ${ }^{\mathrm{TM}}$ ), measuring $40 \times 46 \times 40 \mathrm{~cm}$ (length $\mathrm{x}$ width $\mathrm{x}$ height), located in the School of Psychology animal colony. The rats had unrestricted access to water in their home boxes. Three days before commencing the experiment, they were placed on a restricted food schedule. Each day, half an hour after the end of the daily training session, each tub of rats received a ration of their regular dry chow $(3.4 \mathrm{kcal} / \mathrm{g}$ ) equal to $5 \%$ of the total weight of all rats in the tub. This amount is approximately equal to their required daily energy intake (Rogers, 1979), and took at least $2 \mathrm{~h}$ to be eaten (but was usually finished within $3 \mathrm{~h}$ ).

\section{Apparatus}

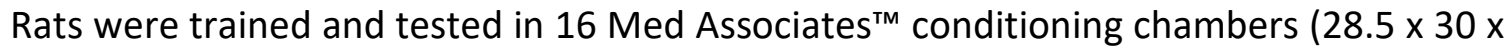
$25 \mathrm{~cm}$ : height $x$ length $x$ depth). The end walls of each chamber were made of aluminum; the sidewalls and ceiling were Plexiglas ${ }^{\mathrm{TM}}$. The floor of the chamber consisted of stainless-steel rods, $0.5 \mathrm{~cm}$ in diameter, spaced $1.5 \mathrm{~cm}$ apart. Each chamber had a recessed food magazine in the center of one end wall, with an infra-red LED and sensor located just inside the 
magazine to record entries by the rat. A small metal cup measuring $3.5 \mathrm{~cm}$ in diameter and $0.5 \mathrm{~cm}$ deep was fixed on the floor of each food magazine. Attached to the food magazine was a dispenser delivering 45 mg food pellets (purified rodent pellets; Bioserve, Frenchtown, NJ). Each chamber was enclosed in a sound- and light-resistant wooden shell. Throughout all sessions, fans located in the rear wall provided ventilation and created background noise (between 61 and $66 \mathrm{~dB}$, depending on the chamber). Experimental events were controlled and recorded automatically by computers and relays located in the same room. White noise (19 dB above background) was presented from a speaker mounted on the wall of each conditioning chamber above and to the left of the food magazine. A steady light $\left(30 \mathrm{~cd} / \mathrm{m}^{2}\right)$ was produced by an incandescent bulb mounted high on the back wall of the soundattenuating shell. Allocation of these two stimuli to the CRf and PRf CSs was counterbalanced between rats. A clicker stimulus (4 clicks per second, each click $24 \mathrm{~dB}$ above background) was emitted from a module (Med Associates, product ENV 135M) located on the wall of the conditioning chamber above and to the right of the magazine. The purpose of the clicker was to serve as a CS that continued to be reinforced with food pellets during sessions when the other two CSs were no longer reinforced. As such, the clicker prevented the extinction of all magazine activity that would otherwise occur if the rats no longer received delivery of any food pellets into the magazine, and which might obscure any differences in extinction of responding to the CRf and PRf CSs themselves.

\section{Procedure}

Prior to the start of conditioning, rats received a 60-min magazine training session during which 20 food pellets were presented on a variable time (VT) 3-min schedule, with no 
stimulus presentations. Rats that ate fewer than half of the pellets were given a second session of magazine training the following day.

After all rats completed magazine training, they commenced daily conditioning sessions 5 days per week for a total of 20 sessions. Each session contained 40 trials, 8 trials of the CRf CS, 24 trials of the PRf CS, and 8 trials with the clicker CS. All CS durations varied randomly from trial to trial, sampled from a uniform distribution. These had a mean duration of $30 \mathrm{~s}$ for the CRf CS (range 2 to $58 \mathrm{~s}$ ), a mean of $10 \mathrm{~s}$ ( 2 to $18 \mathrm{~s}$ ) for the PRf CS, and a mean of $17 \mathrm{~s} \mathrm{(2} \mathrm{to}$ $32 \mathrm{~s}$ ) for the click (this last duration was selected as the geometric mean of the other two CS durations, Meck \& Church, 1983). A single food pellet was delivered at the termination of the CS on every presentation of the CRf CS and of the clicker, but only at the end of 8 of the 24 presentations of the PRf CS. (In the latter case, both the 8 reinforced trials and the 16 nonreinforced trials had a mean duration of $10 \mathrm{~s}$.) Trials of each type were randomly intermixed. The inter-trial interval varied randomly with a mean of $140 \mathrm{~s}$, and the session lasted approximately $100 \mathrm{~min}$.

Sessions 21 to 35 each contained 38 trials. There were 12 compound CS trials in which the CRf CS and the PRf CS were presented simultaneously for a mean duration of $17 \mathrm{~s}$ ( 2 to 32 s), and these trials were not reinforced with food. There were 24 trials with the clicker (mean duration $17 \mathrm{~s}$; range 2 to $32 \mathrm{~s})$ which were all reinforced with a food pellet. Each session also included two probe trials, one with the CRf CS presented alone, and one with the PRf CS presented alone. These trials had a fixed duration of $17 \mathrm{~s}$ and were not reinforced. They occurred at Trial 19 and Trial 26, and the order of the two probes alternated between days and was counterbalanced across rats. The mean inter-trial interval was $140 \mathrm{~s}$, and each 
session lasted approximately 96 min. Photo-beam interruptions by head entry into the magazine were recorded during each CS and each 20-s pre-CS period for all 35 sessions.

\section{Results and Discussion}

A fault with the infra-red detector in one box meant that data was lost on 3 sessions for one rat (Rat 11) which included the first session of extinction (Session 21). Therefore, all data from this rat were excluded from the experiment. Figure 1 shows the mean response rates during the CRf CS, the PRf CS, the compound, and the pre-CS period, for each of the 35 sessions of Experiment 1. The rats acquired responding to the CRf and PRf CSs at similar rates across the 20 conditioning sessions. This was confirmed by a $3 \times 20$ repeated measures ANOVA on response rates during the $\mathrm{CRf} C \mathrm{CS}$, the PRf CS, and the pre-CS period, with Greenhouse-Geisser correction to the degrees of freedom when the assumption of sphericity was violated. There was a significant main effect of CS condition, $F(2,28)=73.10, p<.001$, $\eta^{2} \mathrm{p}=0.84$ and a significant main effect of session, $F(3.1,44)=5.15, p=.003, \eta^{2} \mathrm{p}=0.27$. The interaction between these factors was significant, $F(4.7,65)=11.32, p<.001, \eta^{2} p=0.45$. Orthogonal contrasts on the CS factor showed that there was a significant difference in responding overall between the pre-CS period and the two CSs, $F(1,14)=92.86, p<.001, \eta^{2}$ p $=0.87$, but not between the two CSs themselves, $F(1,14)=3.16, p=.097$.

Figure 1 about here

The data of primary interest are from Sessions 21 to 35 when responding to the two CSs was extinguished. Responding to the compound of the two CSs decreased over the 15 sessions, as did responding during the probe trials with each CS presented on its own. Moreover, responding to the individual CSs differed, with rats responding less to the CRf CS 
than to the PRf CS. A $3 \times 15$ repeated measures ANOVA, with Greenhouse-Geisser corrections, confirmed these impressions. There was a significant main effect of Sessions, $F(4.1,57)=$ $14.95, p<.001, \eta_{p}^{2}=0.52$, confirming that responding decreased over sessions. There was also a significant main effect of CS condition (CRf probes, PRf probes, and Compound), $F(2$, 28) $=25.03, p<.001, \eta^{2}=0.64$, but there was not a significant interaction between the factors, $F(5.5,77)=2.07, p=.072$. To explore the significant main effect across the three CS conditions, we tested 3 pairwise contrasts that compared the two individual CSs to each other and compared each to the compound on the data from Sessions 21 to 35 , and $\alpha$ was adjusted using the Bonferroni correction. These showed that there was a significant difference between probe trials with the CRf CS and with the PRfCS, $F(1,14)=30.63, p<.001, \eta_{p}^{2}=0.69$. Responding during the compound was significantly higher than responding during the CRf CS, $F(1,14)=21.80, p<.001, \eta_{p}^{2}=0.67$, and was significantly lower than responding during the PRf CS, $F(1,14)=11.11, p=.005, \eta_{p}^{2}=0.44$

The difference in responding between probe trials with the PRf CS and probe trials with the CRf CS indicates that extinction of those CSs was not equated even though they were extinguished as a compound. One possible reason for this is that the probe trials themselves provided the opportunity to establish differences in extinction of the two CSs. It is hard to say for sure whether one trial per session with each CS produced meaningful levels of extinction. However, the response rates during the probe trials on Session 21 do speak directly to this issue. Since these were the very first probe trials, there would have been as yet no opportunity for learning on the probe trials to influence responding to the CSs. It is clear from Figure 1 that the difference between responding to the CRf CS and the PRf CS was present on that first probe trial, $t(14)=3.91, p=.002, d=1.01$. A $2 \times 2$ ANOVA with Session as a factor 
(comparing Session 20 with the probe trials on Session 21), showed that the difference between the CSs on Session 21 was itself significantly larger than the difference between the CSs on Session 20 of acquisition, $F(1,14)=10.69, p=.006, \eta^{2}{ }_{p}=0.43$. This shows that there was a difference in extinction between the CSs, despite the fact that they were presented in compound.

It is noteworthy that responding to the compound was lower than responding to one of the individual CSs because one usually sees stronger responding to a compound than to its elements (i.e., summation; Andrew \& Harris, 2011; Kehoe, 1986; Kehoe, Horne, Horne, \& Macrae, 1994; Rescorla \& Coldwell, 1995; Thein, Westbrook, \& Harris, 2008). In the present results, responding to the compound appears to approximate the average of the two individual CSs, rather than their sum. We explain this otherwise surprising observation in terms of the same performance effect that has been described for the PREE. That is, the presence of non-reinforced trials during conditioning of the PRf CS leads to stronger generalisation of conditioning for that CS during extinction. This elevates responding (or opposes extinction) on trials with that CS alone, but a decrement in generalisation on compound trials means that the effect on performance is diminished.

In sum, extinction of responding to the compound of the CRf CS and PRf CS did not result in equivalent extinction of the two component CSs. Probe trials of each individual CS revealed that responding to the PRf CS persisted for longer than responding to the CRf CS, consistent with a preserved PREE. Not only were the two CSs different from one another, but they were both different from the compound: the rats responded significantly more during the PRf CS than during the compound but responded significantly less during the CRf CS than during the compound. The results are incompatible with a strict account of the PREE in terms 
of reduced sensitivity to non-reinforcement during extinction since this would predict that any change in sensitivity to non-reinforcement would affect learning about both CSs together when they are extinguished in compound. The fact that there was still a difference in extinction between the CSs is consistent with descriptions of the PREE as a performance effect in which there is better generalisation of responding to extinction trials with the PRf CS than with the CRf CS, even when any extinction learning about the two CSs is equated. However, the results do not rule out the possibility that changes in sensitivity to non-reinforcement, and thus learning during extinction, do still make some contribution to the PREE. If the PREE is a combination of a performance effect and a learning effect, then even if the approach used here eliminated the difference in learning about non-reinforcement of the two CSs, this would not eliminate the contribution of the performance effect to the PREE when the two CSs are tested individually.

\section{Experiments 2 and 3}

In Experiment 1, the rate of extinction differed between a CRf CS and a PRf CS even when the two CSs were extinguished together as a compound and responding to each individually was measured by occasional probe trials. Thus, it is not only possible to observe the PREE when the PRf and CRf CSs are extinguished in the same subjects, it is even possible when the PRf and CRf CSs are extinguished in the same trial. This PREE would not be predicted if the sole mechanism of the effect were due to a reduction in sensitivity to nonreinforcement after presentation of the PRf CS, since this would affect learning about any other CS present during that trial. Nonetheless, a reduction in sensitivity to nonreinforcement may still contribute to the PREE. That is, extinction of the CRf CS in Experiment 1 may have been slowed by the presence of the PRf CS, but the design of that experiment 
could not identify such an effect because there was no suitable control CS against which to compare extinction of the CRf CS. Experiments 2 and 3 were designed to provide this comparison. Rather than comparing extinction of a CRf CS with a PRf CS when they were extinguished in compound, Experiments 2 and 3 compared the extinction of a target CS, a light (L), when it was extinguished in compound with a PRf CS versus in compound with a CRf CS. If the presence of the PRf CS reduces sensitivity to, and thus learning about, nonreinforcement, then we would see slower extinction of $L$ when it is extinguished in compound with the PRf CS than with the CRf CS.

Both experiments used a between-groups design (see Table 1 for summary). For one group of rats (Group PRf), L was extinguished in compound with a PRf CS; for the other group (Group CRf), L was extinguished in compound with a CRf CS. Responding to L was assessed by a single probe trial per session in which $L$ was presented on its own. To match exactly the training between the two groups, all rats were trained with both the consistently reinforced $\mathrm{CS}, \mathrm{A}$, and the partially reinforced CS, B, even though only one of these CSs was combined with $L$ during extinction. The only difference between Experiments 2 and 3 was in the conditioning schedule of L. In Experiment 2, L was consistently reinforced across Sessions 1 to 20; in Experiment 3, L was partially reinforced (on 1 in 3 trials). We varied the training schedule of L in this way in case L's own reinforcement history interacted with its sensitivity to the reinforcement history of the other CS in the extinction compound.

\section{Methods}

\section{Subjects and Apparatus}

In each experiment, 40 experimentally-naive female albino Sprague Dawley rats were obtained from the same source as in Experiment 1. They were also housed in the same 
manner described for Experiment 1. The rats were trained and tested in 32 Med Associates $^{\mathrm{TM}}$ conditioning chambers. Twenty-four of these were the same as those described for Experiment 1 . The other 8 were very similar but were slightly smaller $(21 \times 30.5 \times 24 \mathrm{~cm}$ : height $x$ length $x$ depth), and the food cup was offset to the left of center in the magazine. These 8 chambers were enclosed in PVC shells, and the constant light stimulus was provided by an LED strip stuck at the top of the back wall of the shell. In each experiment, both groups included 4 rats that were trained and tested in these smaller chambers. The light, white noise, and clicker stimuli described for Experiment 1 were used here. In addition, a high-pitched tone (2.9 kHz, $17 \mathrm{~dB}$ above background) was provided by a piezo buzzer positioned on the floor of the sound-attenuating shell behind each conditioning chamber. The tone and white noise served as the CRf and PRf CSs, A and B, in counterbalanced fashion.

\section{Procedure}

Rats were given magazine training as described for Experiment 1, then divided into two equal groups ( $n=20$ per group) before they commenced daily conditioning sessions 5 days per week for 20 sessions. The sessions were identical for the two groups in each experiment, and consisted of 4 different trial types, with a total of 48 trials per session. In Experiment 2, each session contained: 8 reinforced trials of the CRf CS, A (mean duration $30 \mathrm{~s}$, range 2 to 58 s); 8 reinforced and 16 non-reinforced trials of the PRf CS, B (mean duration $10 \mathrm{~s}$, range 2 to $18 \mathrm{~s}) ; 8$ reinforced trials of the clicker (mean duration $10 \mathrm{~s}$, range 2 to $18 \mathrm{~s}$ ); 8 reinforced trials of $\mathrm{L}$ (mean duration $17 \mathrm{~s}$, range 2 to $32 \mathrm{~s}$ ). In Experiment 3, each session contained: 6 reinforced trials of the CRf CS, A (mean duration $30 \mathrm{~s}$, range 2 to $58 \mathrm{~s}$ ); 6 reinforced and 12 non-reinforced trials of the PRf CS, B (mean duration $10 \mathrm{~s}$, range 2 to $18 \mathrm{~s}$ ); 6 reinforced trials of the clicker (mean duration $10 \mathrm{~s}$, range 2 to $18 \mathrm{~s}$ ); 6 reinforced and 12 non-reinforced trials 
of $L$ (mean duration $17 \mathrm{~s}$, range 2 to $32 \mathrm{~s}$ ). Trials of each type were randomly intermixed. The inter-trial interval varied randomly with a mean of $130 \mathrm{~s}$, and the session lasted approximately $105 \min$.

Sessions 21 to 32 each contained 17 trials and differed between the two groups but were identical across experiments. For Group CRf, there were 8 non-reinforced presentations of the compound LA; for Group PRf, there were 8 non-reinforced presentations of the compound LB. These compound trials had a mean duration of $17 \mathrm{~s}(2$ to $32 \mathrm{~s})$. Intermixed among these compound trials, for both groups, were 8 reinforced trials with the clicker (mean $17 \mathrm{~s}, 2-32 \mathrm{~s}$ ), and a single non-reinforced presentation of $L$ alone (fixed duration of $17 \mathrm{~s}$ ). This probe trial with $L$ occurred on Trial 10. The mean inter-trial interval was $150 \mathrm{~s}$, and each session lasted just over 40 min. Responses were recorded as in Experiment 1.

\section{Results and Discussion}

\section{Experiment 2}

The mean response rates across all 35 sessions for both groups of rats are shown in Figure 2. Two rats in Group CRf failed to acquire reliable levels of responding to any CS above the pre-CS level across the 20 conditioning sessions and were therefore excluded from all analyses. Over the first 20 sessions, both groups acquired responding to A, B, and L, at levels well above the pre-CS period. It also appeared that the rats in Group CRf were responding at a higher rate than rats in Group PRf, despite the fact that both groups received identical schedules of training across these sessions. We conducted a $2 \times(4 \times 20)$ mixed model ANOVA, that included responding to $A, B, L$, and the pre-CS period, across the 20 sessions, in both groups. The difference between the two groups in their overall levels of responding fell short of statistical significance, $F(1,36)=4.07, p=.051$. There was a significant main effect of CS 
condition, $F(2.0,72)=139.82, p<.001, \eta_{p}^{2}=0.80$, that did not interact significantly with group, $F(2.0,72)=2.72, p=.073$. There was a significant main effect of Sessions, $F(5.5,196)$ $=11.69, p<.001, \eta_{p}^{2}=0.25$, that did not interact with group, $F(5.5,196)=1.01, p=.415$, but did interact with CS condition, $F(11.0,397)=18.59, p<.001, \eta_{p}^{2}=0.34$. The triple interaction was not significant, $F(11.0,397)=1.61, p=.094$.

Figure 2 about here

The data of interest are from Sessions 21 to 35 . Figure 2 shows the extinction of responding to the compound stimulus, as well as extinction of responding during probe trials with L. A $2 \times(2 \times 12)$ mixed model ANOVA showed that there was a significant difference in responding overall between the two groups, $F(1,36)=4.46, p=.042, \eta^{2} p=0.11$. There was a significant difference between responding to the compound and responding during $L$ alone, $F(1,36)=12.64, p<.001, \eta^{2} \mathrm{p}=0.26$, and a significant main effect of Sessions, $F(3.3,118)=$ 39.10, $p<.001, \eta_{p}^{2}=0.52$. These two effects interacted, $F(6.8,246)=2.39, p=.023, \eta_{p}^{2}=$ 0.06. The difference between groups did not interact with trial type, $F(1,36)=3.52, p=.069$, or with Session, $F(3.3,118)=0.84, p=.483$, nor was there a 3 -way interaction, $F(6.8,246)=$ $0.67, p=.694$

To test whether extinction of responding to the light differed between the two groups, we compared the two groups on their elevation scores for $L$ (calculated as the response rate during $L$ minus the pre-CS response rate) across the 12 extinction sessions. We used elevation scores to take account of any differences between the two groups in the baseline response rate. We first conducted a $2 \times(12)$ Bayesian repeated measures ANOVA using JASP (JASP_Team, 2018) on the pre-CS response rates to test whether the groups did differ in their baseline responding. This revealed there was more evidence that the groups did not differ 
than evidence for a difference between the groups, $\mathrm{BF}_{01}=3.5$, and strong evidence that there was no interaction between Group and Session, $\mathrm{BF}_{01}=75.7$. The comparison of elevation scores for $L$ between the two groups is shown in the bottom left panel of Figure 2 . A $2 \times(12)$ ANOVA comparing elevation scores to L in Group CRf appeared to be higher than in Group PRf, which was confirmed in the ANOVA, $F(1,36)=8.45, p=.006, \eta_{p}^{2}=0.19$. The ANOVA showed there was also a main effect of Sessions, $F(6.0,215)=20.47, p<.001, \eta_{p}^{2}=0.36$, that did not interact with group, $F(6.0,215)=0.92, p=.482$. The strength of evidence for no interaction between group and session was tested using a $2 \times(12)$ Bayesian ANOVA. This identified strong evidence that there was no interaction between Group and Session, $\mathrm{BF}_{01}=$ 31.0.

The overall higher level of responding in Group CRf was opposite to our prediction that responding would extinguish more slowly in Group PRf, and the difference appeared to have carried over from a difference between the groups in acquisition of responding to L. To test whether extinction of responding to $L$ differed between the groups, after taking into account the difference in levels in responding at the end of conditioning, we normalised each rat's response rate during extinction by dividing its response rate on each extinction session by its response rate on Session 20. These normalised rates are shown in the bottom right panel of Figure 2. There is no difference in the rate of extinction between the groups when response rates are expressed as a proportion of the rate at the end of conditioning. A $2 \times(12)$ ANOVA of these data confirmed that, while there was a significant main effect of Session, $F(7.4,265)=24.33, p<.001, \eta_{p}^{2}=0.40$, there was no overall difference between the groups, $F(1,36)=0.32, p=.573$, nor was there an interaction between Group and Session, $F(7.4,265)$ $=0.30, p=.959$. A Bayesian ANOVA on these normalised rates confirmed that there was 
modest evidence that the two groups did not differ overall, $\mathrm{BF}_{01}=5.3$, and there was strong evidence that that there was no interaction between Group and Session, $\mathrm{BF}_{01}=159.0$.

\section{Experiment 3}

A fault with the infra-red sensor in one box affected registration of magazine activity on Sessions 27 to 32 for one rat in each group. Therefore, we excluded all data from those rats from all analyses. The mean response rates across each of the 32 sessions of the experiment are shown in Figure 3. The rats acquired robust levels of responding during presentations of $A, B$, and $L$, across Sessions 1 to $20 . A 2 \times(4 \times 20)$ mixed model ANOVA, with Greenhouse-Geisser corrections, was conducted on response rates to these 3 CSs, as well as during the pre-CS period, across each of the 20 sessions for both groups. There was no overall difference in response rate between the two groups, $F(1,36)=0.79, p=.381$, and the factor Group did not interact with either of the other factors, largest $F=0.83$, smallest $p=.549$. There was a significant main effect of trial type, $F(1.6,56)=76.12, p<.001, \eta_{p}^{2}=0.68$, as well as a main effect of Session, $F(3.9,140)=23.26, p<.001, \eta_{p}^{2}=0.39$, and an interaction between these factors, $F(6.2,222)=13.27, p<.001, \eta^{2}{ }_{p}=0.27$. Orthogonal contrasts across the trial-type factor showed there was a significant difference between pre-CS response rates and responding during the CSs, $F(1,36)=99.96, p<.001, \eta_{p}^{2}=0.74$, and a significant difference between responding to $L$ and responding to $A$ and $B, F(1,36)=18.71, p<.001, \eta^{2}$ p $=0.34$, but there was no difference in responding to $A$ versus responding to $B, F(1,36)=0.55$, $p=.463$

Figure 3 about here

Responding to the compound stimulus (A-Light for Group CRf, B-Light for Group PRf) decreased over the course of the 12 extinction sessions. Responding during probe trials with 
$\mathrm{L}$ alone also decreased over those sessions. We conducted a $2 \times(2 \times 12)$ ANOVA on the response rates during $L$ and the compound, across the 12 sessions, for both groups. There was no overall difference in responding between the two groups, $F(1,36)=0.08, p=.786$, and the factor Group did not interact with either of the other factors, largest $F=1.75, p=.194$. There was a difference overall in responding during $L$ versus during presentations of the compound, $F(1,36)=12.42, p=.001, \eta_{p}^{2}=0.26$. There was a main effect of sessions, $F(4.6$, $165)=8.24, p<.001, \eta^{2}{ }_{p}=0.19$, that interacted with the difference between $L$ and the compound, $F(5.5,198)=2.41, p=.033, \eta_{p}^{2}=0.06$.

As in Experiment 2, we compared elevation scores for $L$ (responding during $L$ minus pre-CS response rates) between the two groups across the 12 extinction sessions, after first conducting a $2 \times$ (12) Bayesian ANOVA on the pre-CS response rates. This revealed there was slightly more evidence that the groups did not differ than evidence for a difference between the groups, $\mathrm{BF}_{01}=1.68$, and strong evidence that there was no interaction between Group and Session, $\mathrm{BF}_{01}=149.2$. The elevation scores to $\mathrm{L}$ are shown in the bottom plot in Figure 3. Unlike Experiment 2, in this experiment responding to $L$ was very similar between the two groups across the acquisition phase, and therefore the two groups started the extinction phase with very similar levels of responding to L. Across the 12 extinction sessions, responding to $L$ decreased at very similar rates for the two groups. A $2 \times(12)$ ANOVA confirmed that there was a significant main effect of sessions, $F(5.5,198)=5.29, p<.001, \eta_{p}^{2}=0.13$, but no overall difference between the two groups, $F(1,36)=0.00, p=.976$, and no interaction between group and sessions, $F(5.5,198)=0.77, p=.583$. A $2 \times(12)$ Bayesian ANOVA revealed the strength of evidence for these latter two null results. There was moderate evidence that the 
two groups did not differ overall, $\mathrm{BF}_{01}=5.3$, and there was strong evidence that there was no interaction between Group and Session, $\mathrm{BF}_{01}=48$.

\section{Experiment 4}

Neither Experiment 2 nor Experiment 3 have provided any evidence that extinction of a light is affected by the presence of a PRf CS during extinction trials. Indeed, in both experiments, Bayesian analyses showed that there was stronger evidence for no effect of the PRf CS than an effect in the predicted direction. These results argue against any conclusion that the PREE is due to a decrease in sensitivity to non-reinforcement. However, that is the conclusion reached by Rescorla (1999a) based on a series of experiments that tested the acquisition of conditioned inhibition to a stimulus paired with either a PRf CS or a CRf CS. The logic of Rescorla's experiments is similar to that of our own. He tested how much animals learn about a target stimulus when it is presented in compound with either a PRf CS or a CRf CS, and the compound is not reinforced. But where, in our experiments, the target stimulus, $L$, had been previously conditioned and we were measuring extinction of responding to it, in Rescorla's experiments the target stimulus was novel prior to its presentations in compound, and he measured the acquisition of inhibition to that stimulus. Rescorla found that the target stimulus acquired less inhibitory strength if it was conditioned in compound with a PRf CS than if it was conditioned in compound with a CRf CS, implying that animals learn less about non-reinforcement in the presence of a PRf CS than a CRf CS. This would predict that animals would also show less extinction of a target CS that was presented without reinforcement in compound with a PRf CS than with a CRf CS, but we have observed no such effect here.

There are many differences between our experiments and those conducted by Rescorla (1999a), but the one that has the most potential to be illuminating is that he used 
the acquisition of conditioned inhibition to measure learning about non-reinforcement, whereas we measured extinction of conditioned responding. The question that arises is whether we would see a difference in the acquisition of inhibition to a novel target CS when it is presented without reinforcement in compound with either a PRf CS or a CRf CS. This was the objective of Experiment 4. It was conducted as an entirely within-subjects experiment (see Table 2), just as Rescorla's experiments were, but using rats in a Pavlovian magazine approach paradigm rather than pigeons in a Pavlovian key-pecking paradigm. Rats were trained for 20 sessions with a CRf CS, A, and a PRf CS, B, as well as a consistently reinforced clicker, C, to serve as the transfer test CS. Then, for 16 sessions, each session included additional trials in which $A$ was presented in compound with a new stimulus, $X$, and $B$ was presented in compound with a new stimulus, $\mathrm{Y}$, and these compounds were never reinforced. To test the acquisition of inhibition to $X$ and $Y$, each of these sessions also included two nonreinforced probe trials, in one $X$ was presented in compound with $C$ and in the other $Y$ was presented with $C$. Therefore, as $X$ and $Y$ acquire inhibitory strength, they should reduce responding to $C$. The inhibitory strength of $X$ and $Y$ were also assessed in a separate test session at the end of the experiment, which included multiple non-reinforced presentations of the CX and CY compounds, as Rescorla had done. Based on Rescorla's results, we would expect stronger inhibition by $X$ than $Y$, and thus lower levels of responding on $C X$ trials than CY trials.

Table 2 about here

\section{Methods}




\section{Subjects and Apparatus}

Sixteen experimentally-naive female albino Sprague Dawley rats were obtained from the same source as in Experiment 1. They were also housed in the same manner described for Experiment 1 . The rats were trained and tested in the 16 Med Associates $^{\mathrm{TM}}$ conditioning chambers described for Experiment 1 . The light, white noise, tone, and clicker stimuli described previously were used here. In addition, a flashing light $\left(2 \mathrm{~Hz} ; 3.0 \mathrm{~cd} / \mathrm{m}^{2}\right)$ was produced from a $3 \times 3$ array of white LED bulbs, positioned on the floor of the shell in front of conditioning chamber. With the exception of the clicker, which always served as stimulus C, the other four stimuli (steady light, flash, white noise, and tone) were assigned in counterbalanced fashion as CSs $A, B, X$, and $Y$, with the following constraints: $A$ and $B$ were always from different modalities, and $\mathrm{X}$ and $\mathrm{A}$ were from a different modalities, as were $\mathrm{Y}$ and $B$, so that the compounds presented in the inhibition training phase had one auditory and one visual stimulus.

\section{Procedure}

Rats were given magazine training, as described for Experiment 1, before commencing daily conditioning sessions 5 days per week for 20 sessions. In each session, there were 6 reinforced trials of the CRf CS, A (mean duration $30 \mathrm{~s}$, range 2 to $58 \mathrm{~s}$ ), 6 reinforced and 12 non-reinforced trials of the PRf CS, B (mean duration $10 \mathrm{~s}$, range 2 to $18 \mathrm{~s}$ ), and 6 reinforced trials of the clicker (mean duration $17 \mathrm{~s}$, range 2 to $32 \mathrm{~s}$ ). Trials of each type were randomly intermixed. The inter-trial interval varied randomly with a mean of $120 \mathrm{~s}$, and the session lasted approximately $70 \mathrm{~min}$.

Sessions 21 to 36 each contained 56 trials. Trials with A, B, and the clicker continued exactly as during the training phase. In addition, each session included 12 trials in which $A$ and 
$\mathrm{X}$ were presented together as a compound, and 12 trials in which $\mathrm{B}$ and $\mathrm{Y}$ were presented as a compound. These trials had a mean duration of $17 \mathrm{~s}(2$ to $32 \mathrm{~s})$ were not reinforced. The sessions also included a single non-reinforced presentation of $\mathrm{X}$ in compound with the clicker $(C X)$, and a single non-reinforced presentation of $Y$ in compound with the clicker (CY), both with a fixed duration of $17 \mathrm{~s}$. These probe trials always appeared as the $19^{\text {th }}$ and $36^{\text {th }}$ trial in the session, with the order of presentation within the session alternating across days and between groups.

Session 37 was run as a single transfer test. The three individual CSs (A, B, and C) were presented on the same schedules as in Phase 1. In addition, two compound stimuli, CX and $\mathrm{CY}$, were presented without reinforcement. These test compounds were each presented 12 times, with a mean duration of $17 \mathrm{~s}$ ( 2 to $32 \mathrm{~s}$ ). In all sessions, responses were recorded in the manner described for Experiment 1.

\section{Results and Discussion}

Response rates during each trial type across all sessions of the experiment are shown in Figure 4. Across the first 20 sessions, the rats acquired robust levels of responding to CSs $A$ and $B$, well above the pre-CS baseline level, and even higher response rates to $C$. Response rates failed to be recorded for 8 rats during Session 1, and therefore analysis of the training data excluded this session. A 4 × 19 repeated measures ANOVA, with Greenhouse-Geisser corrections, confirmed that there were significant main effects of trial type, $F(2.1,32)=54.44$, $p<.001, \eta_{p}^{2}=0.78$, and Session, $F(4.6,69)=3.04, p=.018, \eta_{p}^{2}=0.17$, as well as a significant interaction between these factors, $F(7.4,111)=4.43, p<.001, \eta^{2} p=0.23$. Orthogonal contrasts comparing different trial types showed that responding during the 3 CSs was significantly higher than during the pre-CS period, $F(1,15)=84.97, p<.001, \eta_{p}^{2}=0.85$, that 
responding to the clicker was significantly higher than to $A$ and $B, F(1,15)=31.67, p<.001$, $\eta_{p}^{2}=0.68$, and there was no difference in responding to $A$ and to $B, F(1,15)=0.50, p=.491$. Figure 4 about here

With the introduction of $A X$ and BY compounds on Session 21, the rats responded to those compounds at a similar level to their responding to $A$ and $B$ alone. But across the next 16 sessions, responding to $A X$ and $B Y$ gradually decreased, while responding to $A$ and $B$ remained high. Across these sessions, responding to $A$ and $B$ diverged somewhat, and the level of responding to $A X$ and $B Y$ also differed slightly. $A 2 \times 2 \times 16$ repeated measures ANOVA confirmed these impressions. There was a significant difference between compound trials ( $\mathrm{AX}$ and $\mathrm{BY}$ ) and single CS trials $(\mathrm{A}$ and $\mathrm{B}), F(1,15)=35.65, p<.001, \eta^{2}{ }_{\mathrm{p}}=0.70$, as well as a significant difference between trials containing $A(A$ and $A X)$ and trials containing $B$ ( $B$ and BY), $F(1,15)=11.97, p=.004, \eta_{p}^{2}=0.44$, and these factors did not interact, $F(1,15)=0.15, p$ $=.702$. There was a significant main effect of sessions, $F(4.7,69)=2.83, p=.025, \eta_{p}^{2}=0.16$, that interacted with the difference between single CS and compound trials, $F(1.6,24)=11.41$, $p=.001, \eta^{2}{ }_{p}=0.43$, but did not interact with the difference between $A$ and $B, F(4.7,70)=$ $1.86, p=.117$, nor was there a 3 -way interaction, $F(4.7,71)=1.57, p=.183$.

The decline in responding to $A X$ and $B Y$ was matched by a gradual decrease in responding to the $\mathrm{CX}$ and $\mathrm{CY}$ compounds. While responding during $\mathrm{CX}$ and $\mathrm{CY}$ decreased below the level of responding to $C$ alone, there was little apparent difference between responding to $\mathrm{CX}$ and $\mathrm{CY}$. A $3 \times 16$ repeated measures ANOVA tested these differences. There was a significant main effect for trial type, $F(1.4,21)=6.69, p=.011, \eta_{p}^{2}=0.31$, but not for Session, $F(4.0,61)=0.72, p=.583$, and there was not a significant interaction between trial type and session, $F(5.9,88)=1.34, p=.249$. Orthogonal contrasts showed that there was a 
difference in responding between trials with $C$ alone and compound trials (CX and CY), $F(1$, $15)=20.11, p<.001, \eta_{p}^{2}=0.57$, and this interacted with a linear trend across sessions, $F(1$, $15)=20.51, p<.001, \eta_{p}^{2}=0.58$. There was, however, no difference between responding to $C X$ and to $C Y, F(1,15)=0.77, p=.396$, and this did not interact with session, $F(1,15)=0.11, p$ $=.746$.

Figure 4 also shows the response rates to these same 3 trial types during the test in Session 37. Responding to both $\mathrm{CX}$ and $\mathrm{CY}$ was lower than to $\mathrm{C}$, consistent with the acquisition of inhibitory strength by $\mathrm{X}$ and $\mathrm{Y}$. There did not appear to be much difference the level of responding to $\mathrm{CX}$ versus $\mathrm{CY}$, and to the extent that there was a difference it appeared that responding to $\mathrm{CY}$ was less than to $\mathrm{CX}$. These conclusions were supported by an ANOVA on the response rates to $C, C X$ and $C Y$. Overall, there was a significant main effect of trial type, $F(1.6$, 24) $=12.72, p<.001, \eta_{p}^{2}=0.46$. Orthogonal contrasts confirmed that responding to $C$ was higher than responding to $C X$ and $C Y, F(1,15)=17.44, p=.001, \eta_{p}^{2}=0.54$, but that there was no difference in responding between $C X$ and $C Y, F(1,15)=1.43, p=.250$.

In this experiment, we failed to find any evidence for a difference in responding to $C X$ versus $\mathrm{CY}$, whether measured using probe trials across the inhibitory conditioning phase of the experiment, or when measured in a separate test session after inhibitory conditioning. We have conducted Bayesian analyses (Gallistel, 2009) on the difference between responding to $\mathrm{CX}$ and $\mathrm{CY}$ to establish the strength of evidence in these data for a null result-that there is in fact no difference in responding to $\mathrm{CX}$ versus $\mathrm{CY}$. For both the probe trial data from Sessions 21 to 36, and for the test data from Session 37, we calculated Bayes factors as the ratio of the marginal likelihoods that the differences between $C Y$ and $C X$ are from a distribution with mean of zero versus a distribution with mean greater than zero (such that 
$\mathrm{CY}>\mathrm{CX}$ ). In both cases, the Bayes factors were always greater than 1 , meaning that the evidence consistently favoured the null hypothesis. For the probe trial data, the odds favouring the null exceeded 3:1 for any prediction of a difference between $\mathrm{CY}$ and $\mathrm{CX}$ that was greater than .044 responses per second. There was strong evidence favouring the null (odds $>$ 20:1) against any predicted difference above 0.09 responses per second. We also computed the Bayes factor for the null against a version of the hypothesis that responding to $\mathrm{CY}$ should be greater than to $\mathrm{CX}$ but which is vague about the size of this effect. In this case, we allowed this vague hypothesis to predict any effect size ranging between no difference between $\mathrm{CY}$ and $\mathrm{CX}$ (i.e., the null hypothesis) up to a difference of 0.11 (the expected value if $Y$ had no effect on responding to $C$ and thus responding to $C Y=C)$. In this case, the odds favoured the null hypothesis by 3.5:1. For the test data from Session 37, the odds favouring the null exceeded 3:1 against any predicted difference greater than or equal to 0.057 , and the odds exceeded 20:1 against there being a difference greater than 0.122 . When comparing the null hypothesis against a vague effect size that ranges between no effect and a maximum effect (when responding to $\mathrm{CY}$ equals responding to $\mathrm{C}$, and thus the difference between $\mathrm{CX}$ and $\mathrm{CY}=0.4)$, the odds favour the null 9.4:1.

There was a notable difference in response rates to the CRf CS, A, and the PRf CS, B, that emerged across Phase 2. This difference emerged in parallel with a difference in responding to $A X$ and $B Y$ across the same sessions, suggesting a common mechanism. The simplest explanation of both differences is in terms of a PREE. That is, the non-reinforced presentations of $\mathrm{AX}$ and $\mathrm{BY}$ produced some extinction of both $\mathrm{A}$ and $\mathrm{B}$, as well as establishing inhibition to $\mathrm{X}$ and $\mathrm{Y}$. Because $\mathrm{B}$ was partially reinforced, responding to $\mathrm{B}$ was more resistant to extinction than responding to $A$, and this effect was evident both in the response rates to $A$ and $B$ individually and in the response rates to the compounds $A X$ and $B Y$. 


\section{Experiment 5}

Contrary to the results reported by Rescorla (1999a), in Experiment 4 we found no evidence for a difference in the strength of inhibition acquired to a stimulus depending on whether it was conditioned by pairing with a PRf CS or a CRf CS. We measured inhibition both using a stand-alone test session at the end of training, as Rescorla had done, but also using probe trials conducted throughout the inhibitory training phase, in case inhibitory strength emerged at different rates in the two cases but had reached the same level by the end of training. Nonetheless, at no stage did we observe evidence that an inhibitor, $\mathrm{Y}$, conditioned in compound with a PRf CS, had weaker strength than an inhibitor, X, conditioned with a CRf CS. Experiment 4 used an entirely within-subjects design, just as Rescorla had done in all his experiments. However, it is possible that generalisation between the stimuli we used may have obscured differences in the strength of inhibitory conditioning. For example, although X and $Y$ belonged to different sensory modalities, which should minimise generalisation between them, $\mathrm{X}$ belonged to the same modality as $\mathrm{B}$, and $\mathrm{Y}$ belonged to the same modality as $A$. If the difference in responding that emerged between $A$ and $B$ across the inhibitory conditioning phase translated into stronger excitation being generalised to $\mathrm{X}$ than $\mathrm{Y}$, this might have cancelled the expected difference in inhibitory strength between $\mathrm{X}$ and $\mathrm{Y}$. There was no opportunity for differential generalisation of excitation in Rescorla's experiments because the excitatory CSs were localised key lights and the inhibitory CSs were diffuse stimuli (white noise or flashing of the house light).

Experiment 5 was conducted to address the concern just raised for Experiment 4. It replicated the basic design of Experiment 4, but incorporated a between-subjects factor to reduce the opportunity for generalisation (see Table 2). Two groups of rats, Group CRf and 
Group PRf, were first trained with a clicker, $\mathrm{C}$, and a white noise stimulus (N) that was either consistently or partially reinforced depending on the group. After 20 sessions of training, compound trials were introduced in which a light, L, was presented with $\mathrm{N}$ and these trials were not reinforced. These sessions should establish $L$ as a conditioned inhibitor. To measure the acquisition of inhibition to $L$, each of these sessions included a probe trial in which $L$ was presented in compound with C. After 20 sessions of this inhibitory training, we conducted a test session to compare responding to $\mathrm{C}$ and to the compound $\mathrm{CL}$, across both groups of rats. Based on Rescorla's (1999a) results, we expected that the difference in responding between $\mathrm{C}$ and $\mathrm{CL}$ should be larger in Group CRf than Group PRf, consistent with weaker inhibitory conditioning of $L$ in the latter group.

\section{Methods}

\section{Subjects and Apparatus}

Thirty-two experimentally-naive female albino Sprague Dawley rats were obtained from the same source and were also housed in the same manner described for Experiment 1 . They were trained and tested in the 32 Med Associates $^{\mathrm{TM}}$ conditioning chambers described for Experiment 2. The light, white noise, and clicker stimuli described previously were used.

\section{Procedure}

Rats were given magazine training, then split into two equal groups $(n=16)$ before commencing daily conditioning sessions 5 days per week for 20 sessions. For Group CRf, each session consisted of 10 reinforced trials of the white noise $(\mathrm{N})$ with a mean duration of $30 \mathrm{~s}$ (range 2 to $58 \mathrm{~s}$ ), and 10 reinforced trials of the clicker $(C)$ with a mean duration of $17 \mathrm{~s}(2$ to 32 s). For Group PRf, each session consisted of 10 reinforced and 20 non-reinforced trials of $N$ (mean duration $=10 \mathrm{~s}$, range 2 to $18 \mathrm{~s})$, as well as 10 reinforced trials of $\mathrm{C}(17 \mathrm{~s}$, range 2 to 
32 s). Trials of each type were randomly intermixed. The inter-trial interval varied randomly with a mean of either $230 \mathrm{~s}$ (for Group CRf) or $120 \mathrm{~s}$ (for Group PRf), and the session lasted approximately $80 \mathrm{~min}$.

Sessions 21 to 40 continued the schedule of trials with $\mathrm{C}$ and $\mathrm{N}$ for each group. Intermixed among these trials were 10 non-reinforced presentations of $\mathrm{N}$ in compound with the light, L. These LN compound trials had a mean duration of $17 \mathrm{~s}(2-32 \mathrm{~s})$. In addition, each session included a single presentation of the compound of $L$ and $C$. This probe trial lasted 17 s and was not reinforced. It occurred on Trial 14 (of 31) for Group CRf, and on Trial 21 (of 51) for Group PRf. The inter-trial interval was approximately 150 s (Group CRf) or 100 min (Group PRf), and the sessions lasted approximately $90 \mathrm{~min}$.

Session 41 was run as a single transfer test for inhibition by L. The two excitatory CSs (N and C) were presented on the same schedules as in Phase 1. Intermixed among these trials were 10 non-reinforced presentations of the compound LC (mean duration $=17 \mathrm{~s}$, range 2 to $32 \mathrm{~s})$. In all sessions, responses were recorded in the manner described for Experiment 1.

\section{Results and Discussion}

The mean response rates across all sessions for both groups in Experiment 5 are shown in Figure 5. Across Sessions 1 to 20, both groups acquired robust levels of responding to presentations of $\mathrm{C}$ and $\mathrm{N}$, well above the pre-CS level. We conducted a $2 \times(3 \times 20)$ mixed model ANOVA on these data. There was a significant main effect of trial type, $F(1.3,40)=$ 136.80, $p<.001, \eta_{p}{ }_{p}=0.82$, and a significant main effect of sessions, $F(4.3,128)=6.89, p<$ $.001, \eta_{p}^{2}=0.19$, and these two factors interacted significantly $F(6.8,202)=9.43, p<.001, \eta_{p}^{2}$ $=0.24$. The overall difference in responding between the two groups was not significant, $F(1$, $30)=3.66, p=.065$, and there was no interaction between group and either of the other 
factors, although it came close for the 3-way interaction, $F(6.8,202)=2.04, p=.054$. Orthogonal contrasts between the trial types showed there was a significant difference between pre-CS responding and responding during the two CSs, $F(1,30)=176.75, p<.001$, $\eta^{2} \mathrm{p}=0.86$, as well as a significant difference between responding to $\mathrm{C}$ and responding to $\mathrm{N}$, $F(1,30)=49.63, p<.001, \eta_{p}^{2}=0.62$.

Figure 5 about here

With the introduction of LN compound trials from Sessions 21 to 40, the rats responded less to that compound than to $\mathrm{N}$. Responding to $\mathrm{LN}$ was lower than $\mathrm{N}$ even on the first session (Session 21), which could mean there was very rapid acquisition of conditioned inhibition to L. However, it is very likely that at least some of the initial difference in responding can be attributed to external inhibition (Pavlov, 1927) arising from the fact that $L$ was completely novel. The important observation is that responding to $\mathrm{LN}$ steadily declined across sessions, as evidence for the acquisition of conditioned inhibition to L. At the same time, probe trials with the compound LC showed that $L$ reduced responding to $C$, also consistent with the acquisition of inhibition to L. We conducted two separate $2 \times(2 \times 20)$ mixed model ANOVAs on these data. The first compared responding during $\mathrm{N}$ and responding during $L N$. There was a significant difference overall between the two trial types, $F(1,30)=$ 90.34, $p<.001, \eta_{p}{ }_{p}=0.75$, and the significant main effect of session, $F(4.8,144)=3.66, p=$ $.004, \eta_{p}^{2}=0.11$, also interacted significantly with the difference between $\mathrm{N}$ and $L N, F(4.3$, 129) $=7.38, p<.001, \eta_{p}^{2}=0.20$. There was a significant difference overall between the two groups, $F(1,30)=6.98, p=.013, \eta_{p}^{2}=0.19$, that did not interact significantly with the effect of trial type, $F(1,30)=3.60, p=.067$, or session, $F(4.8,144)=0.91, p=.574$, but did form part of a significant 3-way interaction, $F(4.3,129)=3.07, p=.016, \eta_{p}^{2}=0.09$. The second ANOVA, 
comparing responding to $\mathrm{C}$ and $\mathrm{LC}$, also confirmed there was a significant difference between the two trial types, $F(1,30)=39.93, p<.001, \eta_{\mathrm{p}}^{2}=0.57$. There was a significant main effect of sessions, $F(5.1,154)=4.2, p=.001, \eta_{p}^{2}=0.12$, that interacted significantly with the difference between $C$ and $L C, F(6.2,185)=2.82, p=.011, \eta^{2}{ }_{p}=0.09$. In this case, the difference overall between the two groups was not significant, $F(1,30)=2.55, p=.121$, nor did it interact with either of the other factors, largest $F=0.97, p=.447$, for the 3-way interaction. The absence of any interaction between Group and the difference between responding to $\mathrm{C}$ and to $L C$ is apparent in the plot in the top right part of Figure 5 . This shows the difference in responding to $\mathrm{C}$ and to $\mathrm{LC}$ (calculated as $\mathrm{LC}-\mathrm{C}$ ) across the 20 sessions for the two groups. The difference between responding to $C$ and to $L C$ increased across the sessions, as identified by the significant interaction between session and trial-type reported above, but this evidence for acquisition of inhibition by $L$ did not differ between the two groups.

The data from the final test (Session 41) are shown in the lower right part of Figure 5. Responding during $\mathrm{CL}$ was lower than during $\mathrm{C}$ for both groups, indicating the $\mathrm{L}$ had acquired inhibitory strength. The magnitude of the difference between $\mathrm{C}$ and $\mathrm{CL}$ appears to be greater in Group PRf than in Group CRf. A 2 x (2) mixed model ANOVA confirmed these impressions. There was a significant difference between responding to $\mathrm{C}$ and to $\mathrm{CL}$, averaged over the groups, $F(1,30)=35.97, p<.001, \eta^{2} \mathrm{p}=0.55$. There was no overall difference in the level of responding between the two groups, $F(1,30)=0.03, p=.873$, but there was a significant interaction between Group and trial type, $F(1,30)=6.98, p<.001, \eta^{2}{ }_{p}=0.19$. This confirms that the difference between responding to $\mathrm{C}$ and to $\mathrm{CL}$ was larger in Group PRf than in Group CRf, and thus $\mathrm{L}$ had a larger inhibitory effect on responding in Group PRf. 
The results from the probe trials with $\mathrm{CL}$ across Sessions 21 to 40 provided no evidence that the acquisition of inhibitory strength to $L$ differed between the two groups, and indeed the results from the test in Session 41 indicated that the inhibitory strength of $L$ was perhaps greater in Group PRf than in Group CRf. These results fail to provide any support for our prediction that the inhibitory strength of $L$ would be weaker in Group PRf. As in the previous experiments, we conducted Bayesian analyses (Gallistel, 2009) of the results of Experiment 5 to ascertain how much evidence we have for the conclusion that there was no difference between the groups in the inhibitory strength of L. The first analysis was performed on the differences in responding to $C$ versus $C L$, averaged over the 20 sessions from Session 21 to 40 . The mean difference score was $0.18(S D=0.15)$ for Group CRf, and $0.21(0.19)$ for Group PRf. We calculated the marginal likelihood that the difference scores for Group PRf were from the same distribution as the difference scores for Group CRf (the null hypothesis) and compared this with the marginal likelihood that the difference scores for Group PRf were from a distribution with a lower mean than that of Group CRf (the hypothesis that L's inhibitory strength would be lower in Group PRf). The resultant Bayes Factors favoured the null hypothesis over the alternative regardless of the hypothesised effect size. The odds favouring the null were small when the predicted effect size of the alternative was also very small, but the odds exceeded 3:1 for any effect size greater than 0.07 responses/s. If the predicted effect size is left vaguely defined and allowed to lie anywhere between no effect and the complete absence of any inhibition by L in Group PRf, then the Bayes factor favours the null over this vague hypothesis by $4.5: 1$.

A similar result was obtained from an analysis of the data from the test on Session 41. The mean difference scores $(C$ minus $L C)$ on this test were $0.23(S D=0.25)$ for Group CRf, and 0.53 (0.44) for Group PRf. Again, the Bayes factor consistently favoured the null hypothesis 
over the hypothesis that the difference for Group PRf would be lower than for Group CRf, and these odds exceeded 3:1 for a predicted effect size greater than or equal to 0.06 responses/s. If the null hypothesis is compared with a vague hypothesis that does not specify how much smaller the difference score is for Group PRf than Group CRf (other than assuming the difference score for Group PRf cannot be negative), the odds favouring the null are 5.5:1.

\section{General Discussion}

The experiments presented here sought to test how the reinforcement history of a CS impacts on learning about non-reinforcement during subsequent extinction or inhibitory conditioning. In Experiment 1, when a CRf CS and PRf CS were extinguished together in compound, the two CSs did not lose excitatory strength at the same rate. Probe trials with each CS alone revealed that responding to the PRf CS extinguished much more slowly than responding to the CRf CS. This constitutes another within-subjects demonstration of the PREE (see also Chan \& Harris, 2017; Harris \& Kwok, 2018; Rescorla, 1999b), but more remarkably it shows the effect even exists within-trial. It shows that resistance to extinction produced by partial reinforcement does not depend on a decrease in sensitivity to non-reinforcement, since such an effect would impact equally on the extinction of both CSs in Experiment 1. Rather, the resistance to extinction must involve, at least in part, either a decrease in learning specifically about the PRf CS (e.g., a reduction in its associability), or some effect on performance, such as stronger generalisation of excitation to presentations of the PRf CS than presentations of the CRf CS during the extinction phase. Nonetheless, Experiment 1 does not rule out the possibility that animals become less sensitive to non-reinforcement in the presence of a PRf CS, and that such a process makes some contribution to the PREE under normal circumstances when the CSs are extinguished individually. 
Experiments 2 and 3 sought evidence that sensitivity to non-reinforcement is reduced in the presence of a PRf CS in such a way as to slow extinction learning. The experiments compared the extinction of responding to a light $(\mathrm{L})$ between two different groups of rats. For Group CRf, L was extinguished in compound with a CRf CS; for Group PRf, L was extinguished in compound with a PRf CS. The conditioning strengths of the PRf and CRf CSs were equated by matching their total rate of reinforcement during conditioning. Extinction of $L$ was assessed by measuring responding on probe trials when $L$ was presented alone. In neither experiment was there any evidence that extinction of $L$ was slowed by the presence of the PRf CS, relative to L's extinction in the presence of the CRf CS. This was true whether $L$ itself had been conditioned with consistent reinforcement (Experiment 2) or partial reinforcement (Experiment 3). Bayesian analyses showed that the data obtained in these experiments favoured the hypothesis that the PRf CS has no effect on extinction of L over the hypothesis that it reduces extinction of $L$.

The findings of these experiments contradict Rescorla's (1999a) conclusion that animals are less sensitive to the effects of non-reinforcement when that outcome follows presentation of a PRf CS than when it follows a CRf CS. Rescorla based this conclusion on evidence that pigeons showed weaker inhibitory conditioning to a diffuse stimulus that was trained in compound with a PRf CS than one trained in compound with a CRf CS. Given this, we conducted Experiments 4 and 5 to test whether, using our experimental procedures, we could replicate Rescorla's findings concerning the acquisition of conditioned inhibition. Both experiments failed to provide evidence for a difference in the strength of inhibitory conditioning established using a PRf CS versus a CRf CS. Experiment 4 used a within-subjects design in which two stimuli underwent inhibitory conditioning, one with a PRf CS and the other with a CRf CS. Unlike Rescorla, we found no evidence for a difference in the strength of 
inhibition acquired by the two stimuli. Experiment 5 used a between-subjects design to compare inhibitory conditioning of a light that was trained either with a PRf CS, for one group, or with a CRf CS, for the other group. There was no evidence that the inhibitory strength acquired to the light was weaker in the first group than in the second group. In both experiments, Bayesian analyses supported the null hypothesis, constituting positive evidence that the reinforcement history of the excitatory CS (PRf vs CRf) had no effect on inhibitory conditioning.

How should we explain the discrepancy between our results and Rescorla's (1999a) findings concerning the acquisition of conditioned inhibition? There are several differences in the experiments that might account for the discrepant results. Perhaps the two most obvious differences are that Rescorla's experiments measured sign tracking responses (pecking a key light) in pigeons whereas we measured goal tracking (magazine activity) in rats. While these differences in species and type of response are not trivial, we know of no reason to expect that these should change the nature of inhibitory conditioning in such a way as to produce the discrepancies between the studies. However, we can identify two other differences between the studies that are potentially more meaningful. One difference is that Rescorla equated the PRf and CRf CSs for number of times they were presented in each training session, whereas we equated the CSs for number of times they were reinforced in each session. Therefore, in Rescorla's experiments there were four times as many reinforced trials of the CRf CS than the PRf CS, whereas in our experiments there were three times as many presentations of the PRf CS than the CRf CS (but the two CSs were equated for total duration of exposure as well as number of reinforced trials). The fact that, in Rescorla's experiments, the CRf CS received many more reinforced trials than the PRf CS might have produced a difference in how effective the CSs were at imparting inhibition. Gottlieb and Prince (2012) 
have shown, in a within-subjects design, that increasing the number of reinforced trials per session produces more persistence of responding under extinction. To the extent that extinction and inhibition involve similar learning processes about non-reinforcement, as was the basis of Rescorla's investigations, we might expect a similar effect of number of reinforced trials on the strength of inhibitory conditioning. In other words, it is possible that the effects on inhibitory conditioning that Rescorla observed were due to differences in the number of reinforced trials he gave the PRf and CRf CSs, rather than the difference in number of nonreinforced trials.

Another, more technical difference between our experiments and Rescorla's (1999a) concerns the nature of the excitatory CS used in the transfer test to assess inhibition. In each of Rescorla's experiments, the test CS itself had a mixed reinforcement history-it was conditioned, then extinguished, and then reconditioned just prior to the transfer test. The clicker CS used for the transfer tests in our experiments had only ever received consistent reinforcement. Rescorla justified his practice of extinguishing and reconditioning the test CS as being necessary to make it "a receptive transfer stimulus for measuring the inhibition controlled by the diffuse stimuli" (Rescorla, 1999a, p 405), something that was not necessary to reveal inhibition in our experiments. This may mean that the nature of the inhibitory control acquired in Rescorla's experiments was different to that acquired in our experiments. In particular, the inhibition in Rescorla's experiments may reflect a more modulatory control over responding, akin to negative occasion setting, which can only influence responding to CSs that have a mixed history of reinforcement (e.g., Holland, 1989, 1991).

Regardless of the reason for the discrepancy between our results and Rescorla's (1999a), our findings show that a PREE can be observed under circumstances when the PRf 
CS does not appear to provoke any loss of sensitivity to non-reinforcement. Thus, whether or not a loss in sensitivity to non-reinforcement can contribute to the PREE, it is not necessary for the effect. Rather, the process responsible for the PREE is something quite specific to the PRf CS itself. One possibility is that it reflects a general decrease in the associability of the PRf CS, such that any learning about the CS is impaired (but see Haselgrove, Esber, Pearce, \& Jones, 2010, for evidence that partial reinforcement increases rather than decreases attention to a CS). Alternatively, the PREE could reflect a deficit in learning specifically about non-reinforcement of that CS. While it should be relatively easy to test the first of these hypotheses, the second is more difficult to test because it offers no predictions for learning about the PRf CS beyond a demonstration of the PREE itself. Nonetheless, a deficit in learning about the PRf CS might be detectable indirectly by measuring its ability to overshadow extinction learning about another CS presented in compound. An opportunity to observe such an effect was provided by Experiments 2 and 3. In both of those experiments, a deficit in learning about the PRf CS could impact on extinction of the light, but rather than reducing its extinction, we would expect to see faster extinction of the light because it would be less subject to overshadowing by the PRf CS (Kamin, 1968; Rescorla, 2003; Taylor \& Boakes, 2002). However, there was no such effect in either of those experiments.

In aiming to test whether animals learn less about non-reinforcement on trials with a PRf CS than on trials with a CRf CS, the 5 experiments presented here relied on the logic that learning about two stimuli in compound is governed by a single (global) error term, as proposed in the Rescorla-Wagner model (Rescorla \& Wagner, 1972). That is, what animals have previously learned about the two stimuli in a compound is combined into a single value (e.g., a single prediction of the US) which then determines how much is learned about both stimuli equally. Of course, if one rejects the idea that learning depends on a global error term, 
then one would not necessarily expect that the presence of a PRf CS in a compound will affect what is learned about the other stimulus. This would be consistent with the results of Experiments 1 to 3 . But one challenge for any model that does not identify learning with a global error term is to explain the acquisition of conditioned inhibition, because, in that phenomenon, what the animal learns about the conditioned inhibitor depends specifically on the presence an excitatory CS (or context). One example of a model that does not use a global error term to explain conditioned inhibition is the Comparator Hypothesis (Miller \& Matzel, 1988; Miller \& Stout, 2007). Rather than using a global error term to drive learning, a comparator process is used to regulate performance. The suppressive effect of a conditioned inhibitor on responding is not due to any inhibitory property of that stimulus itself but is determined by the excitatory strength of its comparator stimulus-the excitatory CS with which it was trained. There is nothing in the model that would specify whether a PRf CS would suppress performance less than a CRf CS, when acting via their inhibitory associates, if each CS has the same apparent associative strength. But then there is nothing in the model that can explain the difference in extinction of a PRf CS and a CRf CS.

Rather than a learning deficit, the PREE may be better understood as a performance effect in which responding to the partially reinforced CS is protected from the impact of extinction learning. Identifying responding as the locus of the effect is more in keeping with the prevailing theoretical accounts of the PREE (Amsel, 1962; Capaldi, 1966, 1994) that attribute the resistance to extinction after partial reinforcement to superior generalisation of responding from conditioning to extinction. The animal's own response to non-reinforcement during partial reinforcement training becomes a cue that is associated with eventual reinforcement, and therefore helps to promote responding under extinction. The challenge for these theories is to explain demonstrations of the PREE using within-subjects designs, 
including in Experiment 1, in which animals are trained with both CRf and PRf CSs on intermixed schedules. In these designs, whatever animals learn about their experience with non-reinforcement during training should impact on responding to both CSs equally under extinction, and therefore eliminate any evidence for the PREE (Amsel, 1962; Pearce, Redhead, \& Aydin, 1997). To account for differences in the extinction of a PRf CS and CRf CS within the same subjects, the effect of partial reinforcement training on performance under extinction must be selective for responding to the PRf CS. That is, the animal must identify its experience of non-reinforcement during training with subsequent reinforcement of the PRf CS specifically, such that the experience of non-reinforcement during extinction selectively promotes responding to the PRf CS and not to the CRf CS. The challenge is to explain how such selectivity can occur when trials of the two CSs are intermixed during training, such that each non-reinforced trial is as likely to be followed by, and thus associated with, reinforcement of the CRf CS as of the PRf CS.

An alternative performance rule to explain the PREE has been offered by informationbased theories of learning which argue that responding to a CS extinguishes when the animal decides that the reinforcement rate of the CS has changed based on the accumulation of evidence that expected (scheduled) reinforcers have been missed (Gallistel, 2012; Gallistel \& Gibbon, 2000). This account explains the PREE equally well for within- and between-subjects designs. In either case, responding to the PRf CS takes longer to extinguish than to the CRf CS because it takes longer for the animal to accumulate evidence of missed opportunities for reinforcement with the PRf CS. These accounts describe the evidence accumulation process as based on temporal coding of reinforcement-the animal has learned that the CS is present for a certain amount of time per reinforcer and uses the cumulative elapsed time since the last reinforcement to estimate the number of missed reinforcers during extinction. But there 
is now sufficient evidence, at least using the magazine approach paradigm with rats, that extinction does not depend on cumulative duration of exposure without reinforcement (Drew, Yang, Ohyama, \& Balsam, 2004; Golkar, Bellander, \& Öhman, 2013; Haselgrove \& Pearce, 2003), and that the PREE itself is not dependent on differences rate of reinforcement per unit time during conditioning (Chan \& Harris, 2017; Harris \& Kwok, 2018; Haselgrove, Aydin, \& Pearce, 2004). Rather, extinction appears to be a trial-based process that progresses with each occasion that the CS is presented without reinforcement (Harris \& Andrew, 2017), and the PREE depends on the proportion of trials, not time, that the CS was non-reinforced during conditioning (Bouton, Woods, \& Todd, 2014; Chan \& Harris, 2017).

If we reframe the information-based account of extinction using trials, rather than time, as the units of reinforcement rate, then the PREE occurs because, under extinction, it takes more trials to accumulate evidence of missed opportunities for reinforcement. This account is not only untroubled to explain evidence for a PREE within-subjects but can even account for the within-trial PREE observed in Experiment 1 when the PRf CS and CRf CS were extinguished together as a compound. In the latter case, animals are identifying each extinction trial of the compound as a missed reinforcement of the CRf CS, and every third trial as a missed reinforcement of the PRf CS. However, it is only when these CSs are presented separately on probe trials that the decision to respond (or quit responding) is expressed differentially in performance, and that decision would occur on an earlier probe trial for the CRf CS than for the PRf CS. Described in this way, we would not expect the light CS in Experiments 2 and 3 to be differentially affected by the simultaneous presence of the PRf CS, versus the CRf CS, because those other CSs would not affect the accumulation of evidence of missed reinforcements of the light, and therefore would not affect the decision to stop responding on probe trials with the light. 
What does this information-based account of extinction and the PREE predict about the acquisition of conditioned inhibition, as investigated in Experiments 4 and 5 ? If animals only notice the absence of the US on every $n^{\text {th }}$ trial after conditioning on a $1 / n$ PRf schedule, then we should see a difference in the acquisition of inhibition when trained against a PRf CS versus a CRf CS. That is, the less frequent expectation of reinforcement of the PRf CS should slow the rate at which inhibition is acquired, just as it is argued to slow extinction. Such an effect was not observed in either Experiment 4 or 5 (although it was observed by Rescorla, 1999a). The fact that similar levels of inhibition were established by the PRf and CRf CSs in our experiments may be because we matched the PRf and CRf CSs for their overall rate of reinforcement per unit time. This implies that the acquisition of inhibition is based on a change in rate of reinforcement per unit time, which was the same for the PRf and CRf CSs, rather than a change in reinforcement rate per trial, which differed between the two CSs. This conclusion is consistent with demonstrations that inhibition is acquired to a stimulus that signals a decrease in reinforcement rate by extending the length of the trial rather than cancelling reinforcement altogether (i.e., the inhibitor signals a change in reinforcement rate per unit time but not per trial, Harris, Kwok, \& Andrew, 2014). This identifies inhibitory conditioning with the same processes responsible for excitatory conditioning, since the acquisition of responding is sensitive to the overall rate of reinforcement and is not affected by differences in reinforcement rate per trial if the overall rate is held constant (as shown in Experiments 4 and 5). 


\section{References}

Amsel, A. (1958). The role of frustrative nonreward in noncontinuous reward situations. Psychological Bulletin, 55, 102-119.

Amsel, A. (1962). Frustrative non-reward in partial reinforcement and discrimination learning: Some recent history and a theoretical extension. Psychological Review, 69, 306-328.

Andrew, B. J., \& Harris, J. A. (2011). Summation of reinforcement rates when conditioned stimuli are presented in compound. Journal of Experimental Psychology: Animal Behavior Processes, 37, 385-393.

Bouton, M. E., Woods, A. M., \& Todd, T. P. (2014). Separation of time-based and trial-based accounts of the partial reinforcement extinction effect. Behavioural Processes, 101, 23-31.

Capaldi, E. J. (1966). Partial reinforcement: A hypothesis of sequential effects. Psychological Review, 73, 459-477.

Capaldi, E. J. (1994). The sequential view: From rapidly fading stimulus traces to the organisation of memory and the abstract concept of number. Psychonomic Bulletin \& Review, 1, 156-181.

Chan, C. K. J., \& Harris, J. A. (2017). Extinction of Pavlovian conditioning: The influence of trial number and reinforcement history. Behavioural Processes, 141, 19-25.

Chan, C. K. J., \& Harris, J. A. (2019). The Partial Reinforcement Extinction Effect: The proportion of trials that are reinforced during conditioning predicts rate of extinction. Journal of Experimental Psychology: Animal Learning and Cognition, in press.

Crawford, L. L., Steirn, J. N., \& Pavlik, W. B. (1985). Within- and between-subjects partial reinforcement effects with an autoshaped response using Japanese quail. Animal Learning and Behavior, 13, 85-92.

Drew, M. R., Yang, C., Ohyama, T., \& Balsam, P. D. (2004). Temporal specificity of extinction in autoshaping. Journal of Experimental Psychology: Animal Behavior Processes, 30, 163-176.

Fitzgerald, R. D. (1963). Effects of partial reinforcement with acid on the classically conditioned salivary response in dogs. Journal of Comparative and Physiological Psychology, 56, 1056-1060.

Fitzgerald, R. D., Vardaris, R. M., \& Teyler, T. J. (1966). Effects of partial reinforcement followed by continuous reinforcement on classically conditioned heart rate in the dog. Journal of Comparative and Physiological Psychology, 62, 483-486.

Gallistel, C. R. (2009). The importance of proving the null. Psychological Review, 116, 439-453.

Gallistel, C. R. (2012). Extinction from a rationalist perspective. Behavioural Processes, 90, 66-80.

Gallistel, C. R., \& Gibbon, J. (2000). Time, rate, and conditioning. Psychological Review, 107, 289-344.

Golkar, A., Bellander, M., \& Öhman, A. (2013). Temporal properties of fear extinction - Does time matter? Behavioral Neuroscience, 127, 59-69.

Gottlieb, D. A., \& Prince, E. B. (2012). Isolated effects of number of acquisition trials on extinction of rat conditioned approach behavior. Behavioural Processes, 90, 34-48.

Harris, J. A. (2015). Changes in the distribution of response rates across the CS-US interval: Evidence that responding switches between two distinct states. Journal of Experimental Psychology: Animal Behavior Processes, 41, 217-231.

Harris, J. A., \& Andrew, B. J. (2017). Time, trials, and extinction. Journal of Experimental Psychology: Animal Learning and Cognition, 43, 15-29.

Harris, J. A., Gharaei, S., \& Pincham, H. L. (2011). Response rates track the history of reinforcement times. Journal of Experimental Psychology: Animal Behavior Processes, 37, 277-286.

Harris, J. A., \& Kwok, D. W. S. (2018). The probability of reinforcement per trial affects posttrial responding and subsequent extinction but not within-trial responding. Journal of Experimental Psychology: Animal Learning and Cognition, 44, 23-35.

Harris, J. A., Kwok, D. W. S., \& Andrew, B. J. (2014). Conditioned inhibition and reinforcement rate. Journal of Experimental Psychology: Animal Learning and Cognition, 40, 335-354.

Harris, J. A., Kwok, D. W. S., \& Gottlieb, D. A. (submitted). The Partial Reinforcement Extinction Effect depends on learning about non-reinforced trials rather than reinforcement rate. 
Harris, J. A., Patterson, A. E., \& Gharaei, S. (2015). Pavlovian conditioning and cumulative reinforcement rate. Journal of Experimental Psychology: Animal Learning and Cognition, 41 137-151.

Haselgrove, M., Aydin, A., \& Pearce, J. M. (2004). A Partial Reinforcement Extinction Effect despite equal rates of reinforcement during Pavlovian conditioning. Journal of Experimental Psychology: Animal Behavior Processes, 30, 240-250.

Haselgrove, M., Esber, G. R., Pearce, J. M., \& Jones, P. M. (2010). Two kinds of attention in Pavlovian conditioning: Evidence for a hybrid model of learning. Journal of Experimental Psychology: Animal Behavior Processes, 36, 456-470.

Haselgrove, M., \& Pearce, J. M. (2003). Facilitation of extinction by an increase or a decrease in trial duration. Journal of Experimental Psychology: Animal Behavior Processes, 29, 153-166.

Holland, P. C. (1989). Transfer of negative occasion setting and conditioned inhibition across conditioned and unconditioned stimuli. Journal of Experimental Psychology: Animal Behavior Processes, 15(4), 311-328.

Holland, P. C. (1991). Transfer of control in ambiguous discriminations. Journal of Experimental Psychology: Animal Behavior Processes, 17(3), 231-248.

Humphrey, L. G. (1939). The effect of random alternation of reinforcement on the acquisition and extinction of conditioned eyelid reactions. Journal of Experimental Psychology, 25, 141-158.

Humphrey, L. G. (1940). Extinction of conditioned psychogalvanic responses following two conditions of reinforcement. Journal of Experimental Psychology, 27, 71-75.

JASP_Team. (2018). JASP (Version 0.9, for Windows).

Jenkins, W. O. (1950). Partial reinforcement: A review and critique. Psychological Bulletin, 47, 193234.

Kamin, L. J. (1968). "Attention-like" processes in classical conditioning. In M. R. Jones (Ed.), Miami symposium on the prediction of behavior: aversive stimulation (pp. 9-31). Miami: Miami University Press.

Kehoe, E. J. (1986). Summation and configuration in conditioning of the rabbit's nictitating membrane response to compound stimuli. Journal of Experimental Psychology: Animal Behavior Processes, 12, 186-195. doi: 10.1037/0097-7403.12.2.186

Kehoe, E. J., Horne, A. J., Horne, P. S., \& Macrae, M. (1994). Summation and configuration between and within sensory modalities in classical conditioning of the rabbit. Animal Learning \& Behavior, 22, 19-26.

Mackintosh, N. J. (1974). The psychology of animal learning. London, UK: Academic Press.

Meck, W. H., \& Church, R. M. (1983). A mode control model of counting and timing processes. Journal of Experimental Psychology: Animal Behavior Processes, 9, 320-334.

Miller, R. R., \& Matzel, L. D. (1988). The comparator hypothesis: A response rule for the expression of associations Bower, Gordon H. (Ed). (1988). The psychology of learning and motivation: Advances in research and theory, Vol. 22. (pp. 51-92). San Diego, CA, US: Academic Press, Inc.

Miller, R. R., \& Stout, S. C. (2007). Sometimes-competing retrieval (SOCR): A formalization of the comparator hypothesis. Psychological Review, 114, 759-783.

Pavlov, I. P. (1927). Conditioned reflexes: An investigation of the physiological activity of the cerebral cortex. (G. V. Anrep, Trans.). New York: Dover.

Pearce, J. M., Redhead, E. S., \& Aydin, A. (1997). Partial reinforcement in appetitive Pavlovian conditioning with rats. Quarterly Journal of Experimental Psychology. B, Comparative \& Physiological Psychology, 50(4), 273-294.

Rescorla, R. A. (1999a). Partial reinforcement reduces the associative change produced by nonreinforcement. Journal of Experimental Psychology: Animal Behavior Processes, 25, 403414.

Rescorla, R. A. (1999b). Within-subject partial reinforcement extinction effect in autoshaping. Quarterly Journal of Experimental Psychology, 52B, 75-87.

Rescorla, R. A. (2003). Protection from extinction. Learning \& Behavior, 31, 124-132. 
Rescorla, R. A., \& Coldwell, S. E. (1995). Summation in autoshaping. Animal Learning \& Behavior, 23(3), 314-326.

Rescorla, R. A., \& Wagner, A. R. (1972). A theory of Pavlovian conditioning: Variations in the effectiveness of reinforcement and nonreinforcement. In A. H. Black \& W. F. Prokasy (Eds.), Classical conditioning II: Current research and theory. (pp. 64-99). New York: AppletonCentury-Crofts.

Rogers, A. E. (1979). Nutrition. In H. J. Baker, J. R. Lindsey \& S. H. Weisbroth (Eds.), The laboratory rat (Vol. 1, pp. 123-152). New York: Academic Press.

Taylor, K. M., \& Boakes, R. A. (2002). Extinction of conditioned tast aversions: Effects of concentration and overshadowing. Quarterly Journal of Experimental Psychology, 55B, 213-239.

Thein, T., Westbrook, R. F., \& Harris, J. A. (2008). How the associative strengths of stimuli combine in compound: summation and overshadowing. Journal of Experimental Psychology: Animal Behavior Processes, 34, 155-166. doi: 10.1037/0097-7403.34.1.155

Wagner, A. R., Siegel, S., Thomas, E., \& Ellison, G. D. (1964). Reinforcement history and the extinction of a conditioned salivary response. Journal of Comparative and Physiological Psychology, 58, 354-358.

Weinstock, S. (1954). Resistance to extinction of a running response following partial reinforcement under widely spaced trials. Journal of Comparative and Physiological Psychology, 47, 318-322. 


\section{Tables}

Table 1. Summary of designs for Experiments 1, 2, and 3.

\begin{tabular}{|c|c|c|}
\hline & Conditioning & Extinction \\
\hline \multicolumn{3}{|c|}{ Experiment 1} \\
\hline & Sessions 1-20 & Sessions 21- 35 \\
\hline A & 30 s 100\% (8 trials) & AB 17 s $0 \%$ (12 trials) \\
\hline B & 10 s $33 \% \quad$ (24 trials) & A $17 \mathrm{~s} \quad 0 \% \quad(1$ trial) \\
\hline & 17 s $100 \%$ (8 trials) & B $17 \mathrm{~s} \quad 0 \% \quad$ (1 trial) \\
\hline & & C 17 s $100 \%$ (6 trials) \\
\hline
\end{tabular}

\section{Experiment 2}

Sessions 1-20

Sessions 21-32

Group CRf
A 30 s $100 \%$ (8 trials)
LA $17 \mathrm{~s} \quad 0 \%$ (8 trials)
B $10 \mathrm{~s} 33 \%$ (24 trials)
L $\quad 17 \mathrm{~s} \quad 0 \% \quad$ (1 trial)
L $10 \mathrm{~s} 100 \%$ (8 trials)
C $17 \mathrm{~s} 100 \%$ (8 trials)
C 17 s $100 \%$ (8 trials)

Group PRf
A 30 s $100 \%$ (8 trials)
LB 17 s $0 \%$ (8 trials)
B $10 \mathrm{~s} 33 \%$ (24 trials)
L $17 \mathrm{~s} \quad 0 \% \quad$ (1 trial)
L 10 s $100 \%$ (8 trials)
C $17 \mathrm{~s} 100 \%$ (8 trials)
C $17 \mathrm{~s} 100 \%$ (8 trials)

\section{Experiment 3}

Sessions 1-20

Sessions 21-32

Group CRf
A 30 s $100 \%$ (6 trials)
LA $17 \mathrm{~s} \quad 0 \%$ (8 trials)
B $10 \mathrm{~s} 33 \%$ (18 trials)
L $\quad 17 \mathrm{~s} \quad 0 \% \quad$ (1 trial)
L $10 \mathrm{~s} 33 \%$ (18 trials)
C $17 \mathrm{~s} 100 \%$ (8 trials)
C 17 s $100 \%$ (6 trials)

Group PRf
A $30 \mathrm{~s} 100 \%$ (6 trials)
LB 17 s $0 \%$ (8 trials)
B $10 \mathrm{~s} 33 \%$ (18 trials)
L $17 \mathrm{~s} \quad 0 \% \quad$ (1 trial)
L $10 \mathrm{~s}$ 33\% (18 trials)
C 17 s $100 \%$ (8 trials)
C $17 \mathrm{~s} 100 \%$ (6 trials)

Note: The mean duration (in seconds) of each CS, and the percentage of trials reinforced with a food pellet are specified. The number of trials for each CS per session are in parentheses. 
Table 2. Summary of designs for Experiments 4 and 5.

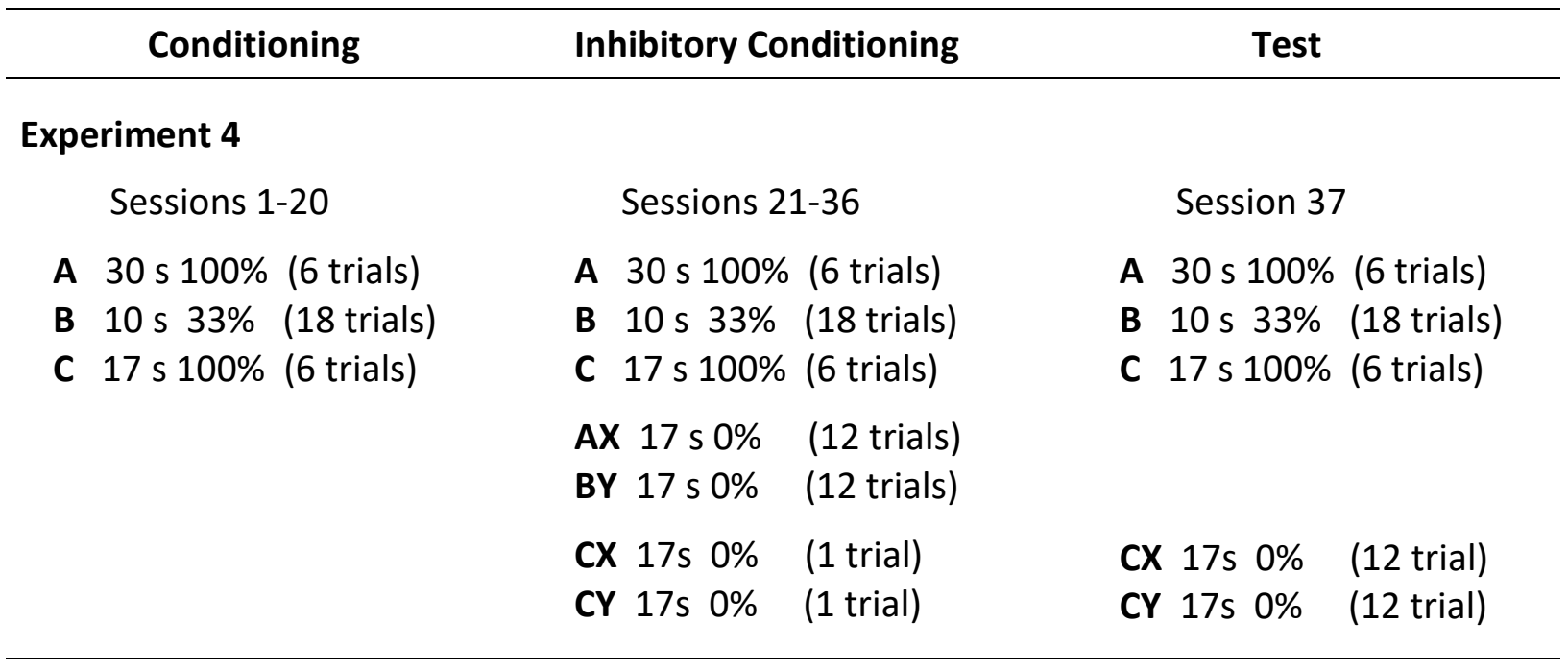

\section{Experiment 5}

Sessions 1-20

Group CRf

N 30 s $100 \%$ (10 trials)

C $17 \mathrm{~s} 100 \%$ (10 trials)

N 30 s $100 \%$ (10 trials)

N 30 s $100 \%$ (10 trials)

C $17 \mathrm{~s} 100 \%$ (10 trials)

LN 17 s $0 \%$ (10 trials)

LC $17 \mathrm{~s} \quad 0 \% \quad$ (1 trial)

Group PRf

N 10 s $33 \%$ (30 trials)

C $17 \mathrm{~s} 100 \%$ (10 trials)

\section{Session 41}

C $17 \mathrm{~s} 100 \%$ (10 trials)

LC $17 \mathrm{~s} \quad 0 \% \quad$ (10 trials)
N 10 s $33 \%$ (30 trials)
C $17 \mathrm{~s} 100 \%$ (10 trials)
LN $17 \mathrm{~s} \quad 0 \%$ (10 trials)
LC $17 \mathrm{~s} \quad 0 \%$ (1 trial)

A 30 s $100 \%$ ( 6 trials)

C 17 s $100 \%$ (6 trials) 


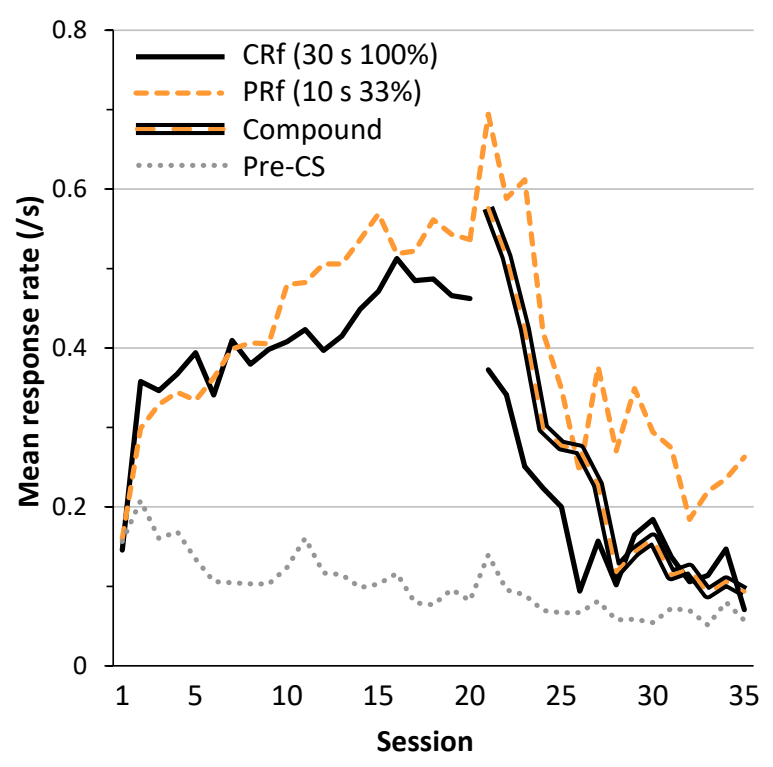

Figure 1. Mean response rates during the continuously reinforced (CRf) CS, the partially reinforced (PRf) CS, the compound of the two CSs, or the pre-CS interval, on each session of Experiment 1. 

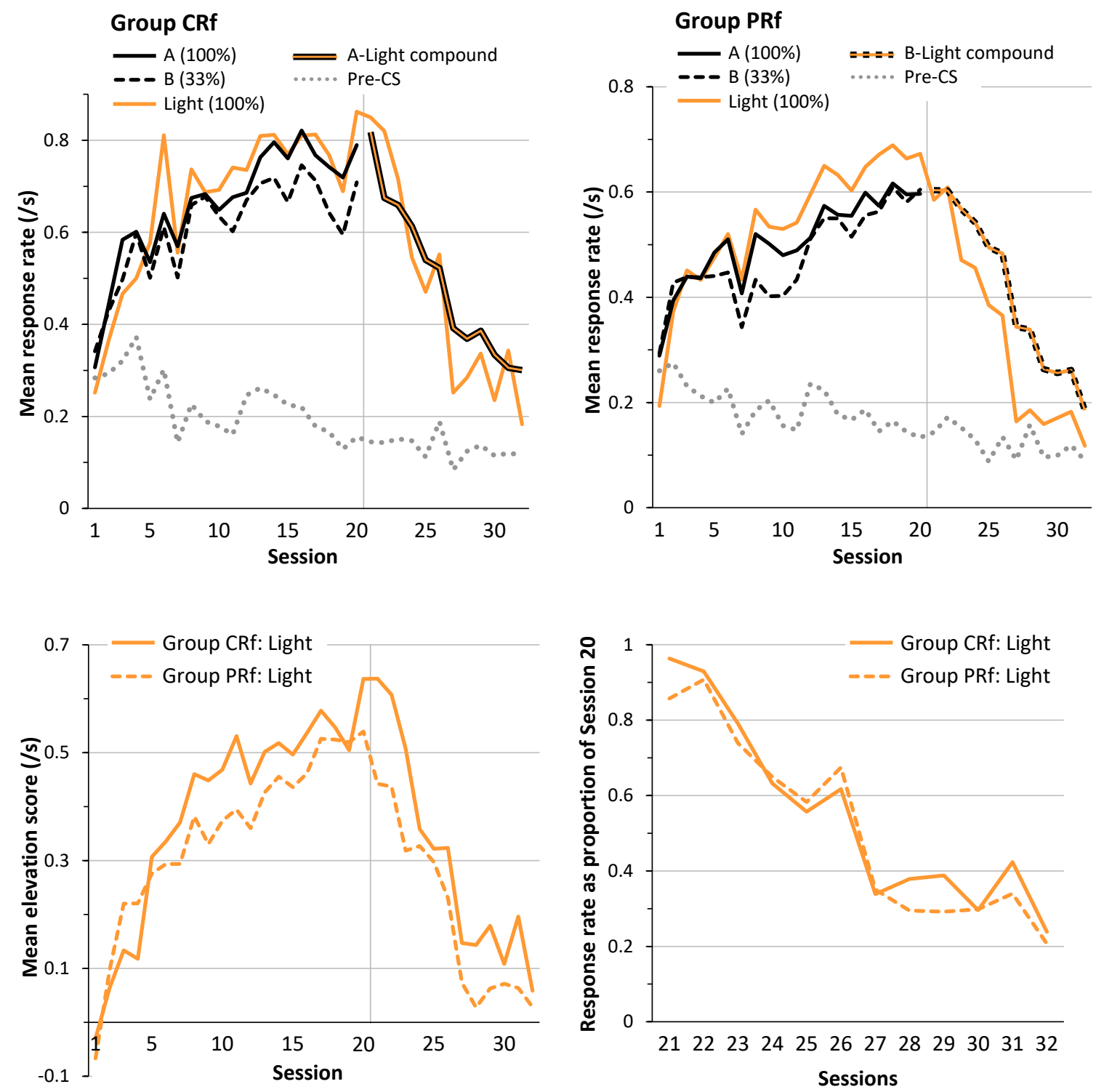

Figure 2. Mean response rates during each CS and the pre-CS interval, on each session of Experiment 2, for Group CRf (upper left plot) and Group PRf (upper right plot). The lower left plot shows the mean elevation score (response rate during the CS minus response rate in the pre-CS interval) for the light in both groups. The lower right plot shows both groups' response rates to the light, on each of the 12 extinction sessions, after each rat's response rate was normalised by being divided by its response rate to the light on Session 20. 

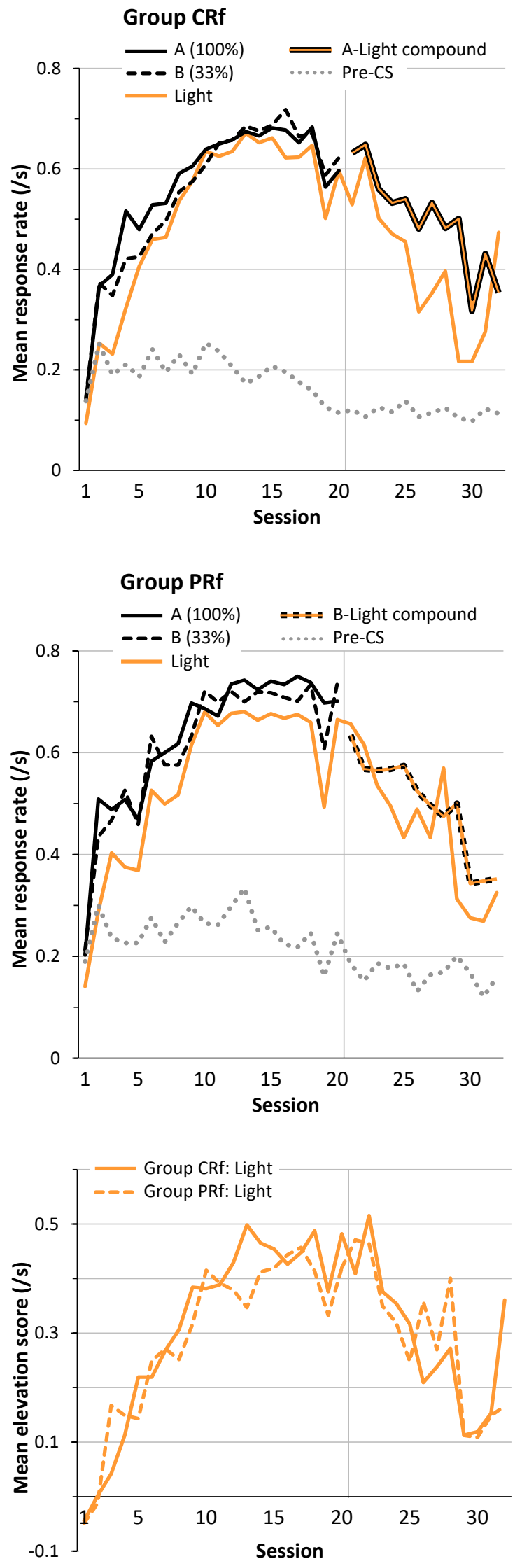

Figure 3. Mean response rates during each CS and the pre-CS interval, on each session of Experiment 3, for Group CRf (top plot) and Group PRf (middle plot). The bottom plot shows the mean elevation score (response rate during the CS minus response rate in the pre-CS interval) for the light in both groups. 

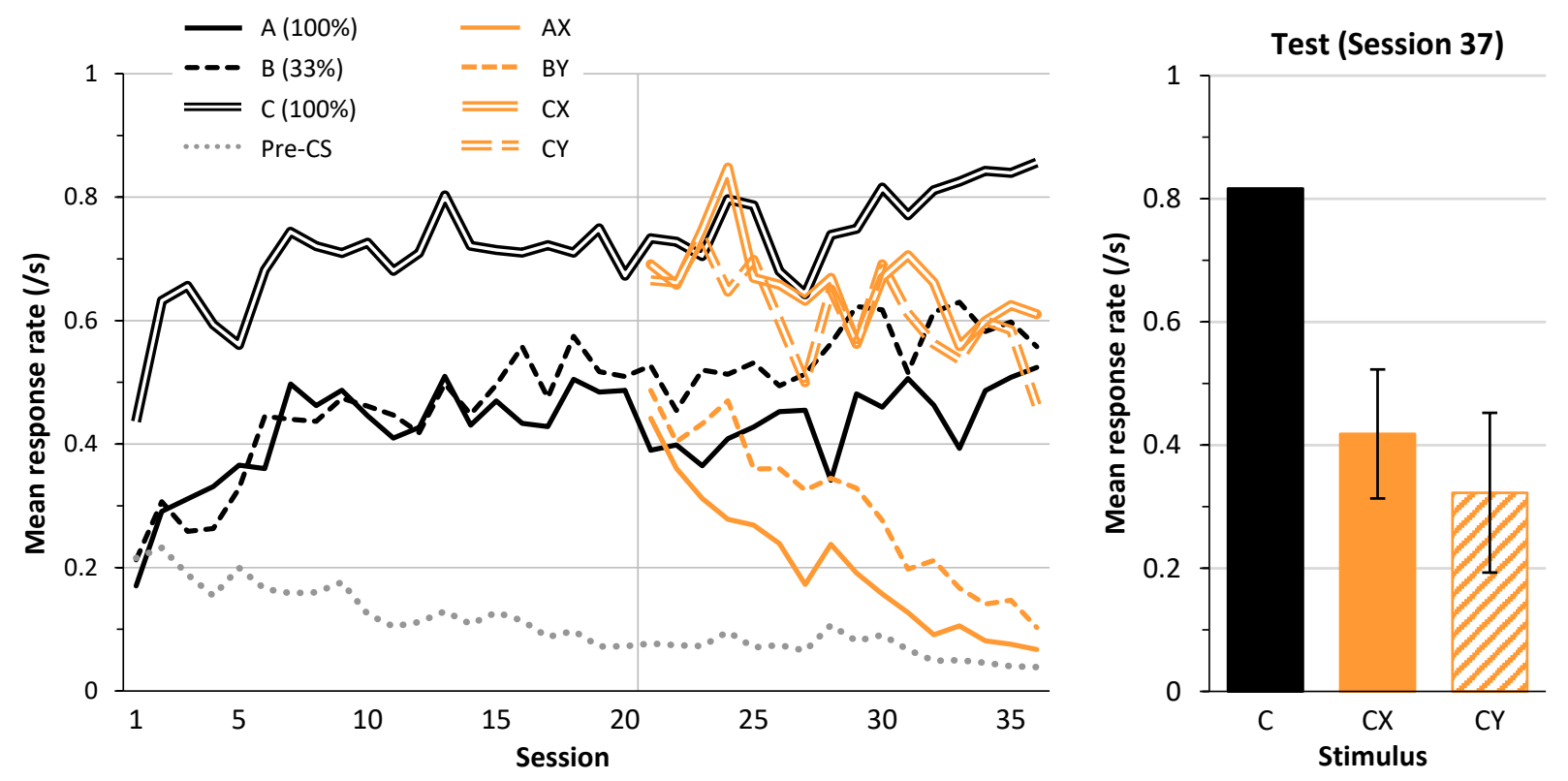

Figure 4. Left: Mean response rates during each CS or compound, and during the pre-CS interval, on each of the first 36 sessions of Experiment 4. Right: Mean response rates to C, CX, and CY during the test on Session 37. Error brackets on CX and CY show the +/standard error (within subjects) of the mean of the difference between responding to the compound and responding to $\mathrm{C}$ (i.e., $\mathrm{CX}-\mathrm{C}$, and $\mathrm{CY}-\mathrm{C}$ ) . 

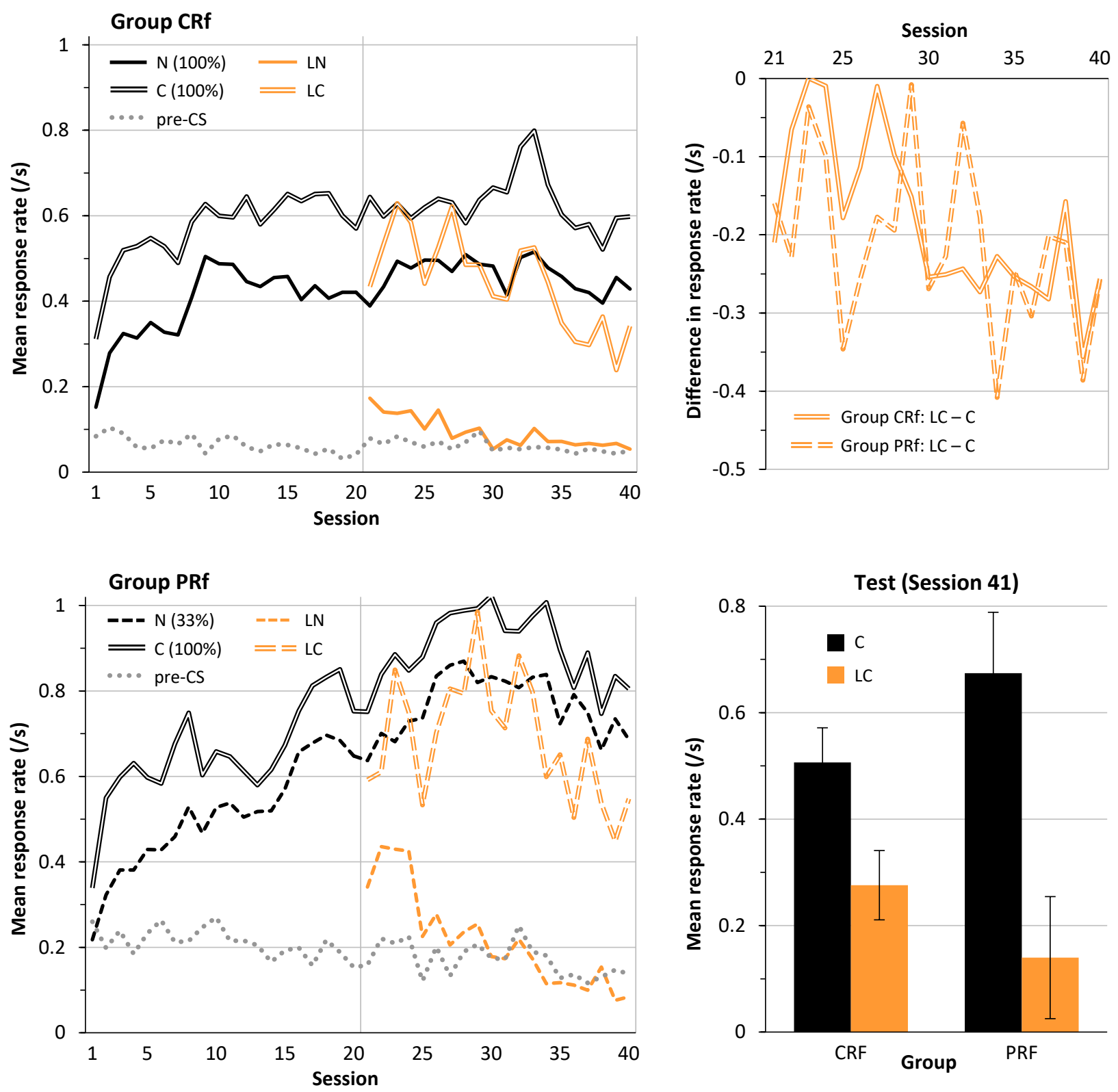

Figure 5. Left panels: Mean response rates during each CS or compound, and during the pre-CS interval, on each of the first 40 sessions of Experiment 5 for rats in Group CRf (top) and rats in Group PRf (bottom). Top right: The difference in response rate between LC and $\mathrm{C}$ on each of the 20 sessions of inhibitory conditioning for both groups. Bottom right: Mean response rates to $C$ and $L C$ during the test on Session 41. Error bars show the +/standard error (within subjects) of the mean of the difference between responding to LC and responding to $C$ for each group. 